\title{
Numerical optimization of combined heat and power Organic Rankine Cycles - Part B: Simultaneous design \& part-load optimization
}

\author{
Federico Capra, Emanuele Martelli* \\ Politecnico di Milano, Department of Energy, Via Lambruschini 4, 20156 Milano, Italy
}

\section{ABSTRACT}

This two-part paper proposes an approach based on state-of-the-art numerical optimization methods for simultaneously determining the most profitable design solution and part-load operation of Combined Heat and Power Organic Rankine Cycles. Compared to the usual design practice, the important advantage of such an approach is to consider the part-load performance of the Organic Rankine Cycle at the design stage. In this second part (Part B), first the part-load model and optimization algorithm are presented and tested. Then, the part-load optimization algorithm is combined with the design optimization algorithm proposed in Part A, and the simultaneous approach is applied to a real-world test case. Computational results show that, with respect to a design optimized for full-load equivalent hours, the solution opti-mized for part-load operation has a lower investment cost, better part-load efficiencies, and thus up to $22 \%$ higher annual profit. The optimized part-load control strategy uses the sliding-pressure mode in the high-load range, and a combination of sliding-pressure and throttling in the low-load range.

\section{Introduction}

In Part A [1] of this two-part paper, we have proposed a model and an effective algorithm for optimizing the design of biomassfired CHP (Combined Heat and Power) ORCs (Organic Rankine Cycles). Given the full-load value of the thermal power required by the heat user (e.g., district heating network) and the objective function which needs to be maximized (e.g., net electric efficiency or annual profit of the plant), the algorithm determines the optimal design of the ORC plant including boiler, cycle and turbine variables. As far the turbine is concerned, the algorithm determines the optimal number of turbine stages, rotational speed and load of each stage. The design optimization problem is tackled with a black-box approach: PGS-COM [2], a derivative-free optimization algorithm, explores the solution space of independent design variables (pressures of evaporation and condensation, pinch point temperature differences of heat exchangers, superheating degree, turbine rotational speed, maximum pressure ratios of stages) and, for each sampled solution, a Matlab routine (the black-box) works out the preliminary design, costs and performance assessment of the biomass-fired boiler, cycle and turbine. In this way, the algorithm

\footnotetext{
* Corresponding author. Tel.: +39 0523356813; fax: +39 0523623097 E-mail address: emanuele.martelli@polimi.it (E. Martelli).
}

performs the simultaneous optimization of the main variables of the cycle, heat exchangers, and turbine. The objective function to be maximized is the annual profit (taking into account of investment and operating costs). The algorithm is applied to optimize the design of a biomass-fired CHP ORC plant providing 5.3 MW of thermal power to a district heating network. The optimization is repeated considering three electricity selling price $(80,110$ and $140 € / \mathrm{MWh})$ and two different working fluids, toluene and $\mathrm{MDM}\left(\mathrm{C}_{8} \mathrm{H}_{24} \mathrm{O}_{2} \mathrm{Si}_{3}\right.$ octamethyltrisiloxane).

In this second part (Part B), we first present and test a novel part-load operation optimization model for CHP ORCs, and then we combine it with the design optimization model presented in Part A to accurately evaluate the impact of the part-load behavior on the design of the plant. The resulting two-stage algorithm allows to assess the optimal plant design and size taking into account of the expected heat demand duration curve and part-load performance of the cycle.

The part-load model allows to determine the optimal control strategy of the ORC (e.g., sliding pressure, constant pressure with throttle valve, or any combination of both) and operative variables which maximize the economic profit at each load. Following the "equation oriented" approach (the model of the plant is expressed in the form of a system of algebraic equations which are tackled all at once [3]), the part-load operation problem is formulated as an optimization problem, namely, a (NLP) (Non Linear Program), and 
solved with a specific algorithm, i.e., Sequential Quadratic Programming.

\subsection{Possible part-load operation strategies}

Biomass-fired ORC plants typically employ an axial-stage turbine with fixed geometry and without partial admission valves (which would allow to reduce the turbine admission area so as to compensate the lower fluid flow rate). The off-design characteristic curve of such a turbine can be approximated by assuming that the non-dimensional flow rate $\varphi$ remains fairly constant,

$\varphi=\frac{\dot{m}_{\mathrm{IN}, \mathrm{T}} \sqrt{\gamma R T_{\mathrm{IN}, \mathrm{T}} z_{\mathrm{IN}, \mathrm{T}}}}{p_{\mathrm{IN}, \mathrm{T}} \mathrm{A}_{\mathrm{T}}} \cong$ const.

In Eq. (1) $\dot{m}_{\mathrm{IN}, \mathrm{T}}$ denotes the turbine inlet mass flow rate, $T_{\mathrm{IN}, \mathrm{T}}$ and $p_{\text {IN,T }}$ are respectively the total temperature and pressure at turbine inlet, $\gamma$ denotes the ratio between constant pressure and constant volume specific heat capacity of the fluid, $R$ is the ideal gas constant, $A_{T}$ is a reference turbine area (e.g., cross-sectional area), while $z_{\mathrm{IN}, \mathrm{T}}$ is the compressibility factor (which has been added to take into account of the real gas effect of the fluid [4]). Eq. (1) implies that, when the cycle load (i.e., output power) must be decreased, a decrease of the working fluid flow rate $\dot{m}_{\text {IN.T }}$ must be compensated by a decrease of the turbine inlet pressure. Indeed, the turbine inlet temperature (equal to the superheating temperature of the cycle) is usually kept close to the maximum allowed value (so as to preserve the cycle efficiency) and the turbine area is constant (no partial admission). Thus, Eq. (1) states that the fluid mass flow rate is essentially proportional to the turbine inlet pressure, and then at part-load such a pressure must be decreased. For this reason, the three possible part-load control-strategies correspond to three ways of reducing the turbine inlet pressure:

1) sliding-pressure: the evaporation pressure is decreased by properly adjusting the feed-pump pressure head;

2 ) throttling: the evaporation pressure is kept constant (at the fullload/design value) and a valve, placed at the turbine admission, is partially closed to cause a proper pressure reduction;

3) hybrid: a proper combination of the two basic modes (i.e., sliding-pressure and throttling) is used.

\subsection{Previous works on part-load models and optimization}

As for the part-load model and optimization approach, it is worth noting that, although different part-load models have been proposed, to the best of our knowledge, none of them adopts the "equation oriented" approach. All of them use sequential simulation codes, either commercial (e.g., Aspen Plus) or specifically developed by the authors, which compute the cycle variables and part-load performance for fixed independent control variables. Part-load models for ORCs have been proposed by different authors. Sun and $\mathrm{Li}$ [5] propose a rather detailed part-load model of a heat recovery ORC plant. To solve it, the authors develop a plant simulation code whose input (independent) control variables are the working fluid mass flow rate, the condenser fan air mass flow rate, and the turbine inlet pressure. The optimization of the partload performance is then carried out by means of the derivativefree Rosenbrock's algorithm [6]. Munoz et al. [7] study the partload performance of gas turbine - ORC combined cycles looking for the optimal control strategy. However, neither the part-load model nor the optimization approach is detailed. Ghasemi et al.[8] have developed a model for the optimal operation of an existing binary geothermal power plant. The model is implemented in
Aspen Plus and has as independent control variables the superheating degree and the evaporation pressure. The flowsheet is solved for fixed independent control variables with the sequential approach [3]. After validation on the basis of a considerable set of experimental data, the model is used to optimize the plant operation strategy for different ambient temperatures. To optimize the two control variables, the authors use both a brute force discretization approach and (for solution refinement) the Sequential Quadratic Programming algorithm available in Aspen Plus.

Calise et al. [9] have implemented two sequential simulation codes in the Engineering Equation Solver environment [10], a first one for optimizing the design, and a second one for simulating the off-design performance of ORCs powered by medium temperature heat sources. While it is stated that the design is numerically optimized with the Golden Section Search algorithm, nothing is specified about the optimization of the off-design control strategy.

Manente et al. [11] optimize the off-design operation of a geothermal binary ORC for different brine temperatures and ambient temperatures. They develop a Simulink [12] model including thermal and mass capacities so as to reproduce the transient behavior of the cycle. The independent control variables (pump rotational speed, opening degree of the turbine nozzles and mass flow rate of condenser air) are optimized by means of the SQP (Sequential Quadratic Programming) algorithm available in the Matlab Optimization Toolbox [13] which uses the Simulink model as a black-box.

Wang et al. [14] develop a Matlab off-design model of a solarpowered ORC to determine system behavior under changes of ambient temperature, thermal oil flow rate, and solar radiation. The operation strategy is not numerically optimized.

Hu et al. [15] analyze an ORC for geothermal heat sources. First the authors design the main cycle components, the radial turbine and the heat exchangers. Then, the performance curves of the components are predicted on the basis of their geometrical features and are integrated within an off-design model of the cycle. The sliding-pressure control strategy is imposed and a sequential solution algorithm is coded to solve the off-design model. The algorithm is applied to determine the cycle and turbine performance for different brine temperatures, brine flow rates and condensing temperatures. The control strategy is not numerically optimized.

Ibarra et al. [16] propose a part-load operation model for a small subcritical ORC featuring a scroll expander. The model is developed in Matlab and considers only the main components of cycle: scroll expander, recuperator and pump. The model receives as inputs the sizes of the components of the cycle from a design model. The part load model simulates the part-load operation varying four parameters: maximum temperature of the cycle, evaporation pressure, expander speed and condensation temperature. The best operation strategy is assessed with a sensitivity analysis.

As far as the combined analysis of design and part-load operation of ORCs is concerned, the works of Lecompte et al. [17] and Toffolo et al. [18] are certainly worth citing. Instead of performing the off-design analysis of just the cycle option with optimized design features (e.g., maximum efficiency at design conditions as in Refs. $[19,20])$, they select a set of promising design options and then optimize and analyze their off-design performance to pick up the best design.

Lecompte et al. [17] propose a strategy for optimizing the design of ORCs which takes into account of the part-load performance of the cycle over the expected year of operation. Their study is focused on a ORC recovering waste heat from an internal combustion en-gine with time-dependent load. They want to determine the best cycle design for the expected yearly scheduling of the engine and ambient temperature (affecting condenser performance). Hence, they define a grid of nominal design conditions (ambient 
temperature and thermal power provided by the engine), and for each point they determine (1) the design variables which minimize the specific (nominal) investment cost with the Nelder-Mead method [21], (2) the part-load map of the optimized cycle expressing the net power output as a function of the ambient temperature and engine load, (3) the behavior of the optimized cycle over the year and the actual annual specific cost. Once the actual annual specific cost of each grid point is computed, a polynomial model is regressed and used to determine the optimal design condition (ambient temperature and thermal power provided by the engine) and associated design variables. It is important to note that the authors optimize the part-load performance of the ORC by means of a Matlab simulation code and the golden section search algorithm [22] which determines the optimal independent control variables (mass flow rate of cooling air to the condenser, and mass flow rate of the heating fluid).

Toffolo et al. [18] optimize the design of ORCs for binary geothermal power plants. The cycle configuration (heat exchanger network) and variables (working fluid mass flow rate, evaporation pressure, condensation pressure and superheating degree) are optimized for the maximum electric efficiency with the HEATSEP method [23] for two working fluids (isobutene and R134a). The Sequential Quadratic Programming algorithm of the Matlab Optimization Toolbox [13] optimizes the intensive cycle variables while the working fluid flow rate is adjusted within the problem table algorithm which handles the heat integration between hot and cold streams. Then the capital cost is evaluated not only for the maximum efficiency design but also for a set of neighboring suboptimal solutions. For each selected solution, the electricity generated over the operating year is assessed with yearly simulations of the plant operation with the off-design model presented in Ref. [11] so as to take into account of ambient temperature variations. The best solution in terms of minimum levelized cost of electricity, which does not coincide with the maximum efficiency design, is picked up from the set of neighboring solutions.

\subsection{Contribution of this work}

This work addresses the following three open challenges:

- develop an equation-oriented part-load model of biomass-fired ORCs suitable for the optimization of the control strategy and show its convergence features;

- determine the best control strategy for biomass-fired ORCs over a wide range of loads;

- tackle the simultaneous optimization of design and part-load operation so as to determine, early at the design stage, the plant design with optimal features for the expected operation schedule.

As for the last challenge, it is important to note that the works of Lecompte et al. [17] and Toffolo et al. [18] do not address the simultaneous optimization of cycle design and part-load operation. Lecompte et al. [17] simplify the problem by optimizing the design with respect to the specific investment cost rather than the annual profit or net present value. Since the specific investment cost does not depend on the part-load performance, this allows them to optimize the design without solving for each sampled design solution the part-load model. Indeed, in their work the part-load operation is computed only for the minimum specific investment cost designs. Similarly, Toffolo et al. [18] optimize the plant design for the maximum design-condition efficiency, and then they analyze and optimize the off-design performance only for a limited set of design solutions in the neighborhood of the maximum efficiency one. Thus, for the facts that (i) the design optimization step considers an objective function depending only on design performance indexes and not depending on the off-design performance, (ii) the off-design analysis and optimization is carried out only for a limited set of design solutions selected on the basis of heuristic criteria, the approaches of Lecompte et al. [17] and Toffolo et al. [18] are not rigorously addressing the simultaneous optimization of cycle design and off-design operation. Thus, they may overlook the optimal cycle design for part-load operation.

The ultimate goal of this work is to tackle the challenging simultaneous design and part-load operation problem by (i) proposing an efficient decomposition approach to solve the simultaneous design and part-load operation problem, (ii) identifying ad hoc optimization algorithms, (iii) showing the advantages of such a simultaneous optimization approach compared to the usual design practice.

\section{Part-load optimization}

This section details the part-load optimization model of the ORC. The plant scheme is reported in Fig. 1. It is made of a biomassfired boiler, a loop of hot oil transferring heat from the boiler to the cycle, a heat exchanger in which the working fluid is economized, evaporated and superheated, a turbine, a regenerator, and a condenser which supplies thermal power to a heat user (e.g., a building or a district heating network) through a water loop. It is important to note that, with respect to the scheme considered in the first part of this work (Part A [1]), a turbine bypass stream has been added in order to increase the operational flexibility. Since the turbine bypass connects the boiler outlet directly to the condenser inlet, it allows to reduce the turbine power and increase the condenser thermal power at fixed boiler load. At the design stage, the bypass allows to design the plant for a nominal condenser thermal power lower than the peak value requested by the heat user (i.e., oversize the plant with respect to the heat demand). Then, during operation, the bypass stream flow rate can be adjusted so as to satisfy the heat demand (opening its valve when the heat de-mand is greater than the nominal condenser thermal power considered at the design stage).

\subsection{Part-load model and optimization problem}

Given the thermal power $\dot{Q}_{\text {USER,t }}$ requested by the heat user at a certain operating period $t$ of duration $\Delta t_{t}$, the part-load optimization model allows to determine the optimal control strategy of the ORC (e.g., sliding pressure, constant pressure with throttle valve, or any combination of both) and the operative variables (pressure, temperature, mass flow rate of each stream) which maximize the economic profit.

The model is built on the following key assumptions:

- the main heat exchanger and the condenser are "oncethrough" (i.e., in the main heat exchanger, the extensions of the econo-mizer, evaporator and superheater sections can vary depending on the operative conditions and fluid flow rate; in the condenser, the desuperheating section and the condensation sections can vary with the load);

- the water flow rate and the oil flow rates can be varied;

- the temperatures of the water loop can be varied but they must be higher than the values required by the heat user;

- the hot oil temperature $T_{\mathrm{V} 2}$ (see Fig. 1 ) is kept constant, equal to the maximum value allowed by the oil, whole temperature $T_{\mathrm{V} 1}$ can be varied.

The set of input data of the part-load model is made of the input economic parameters related to plant operation (electricity and 


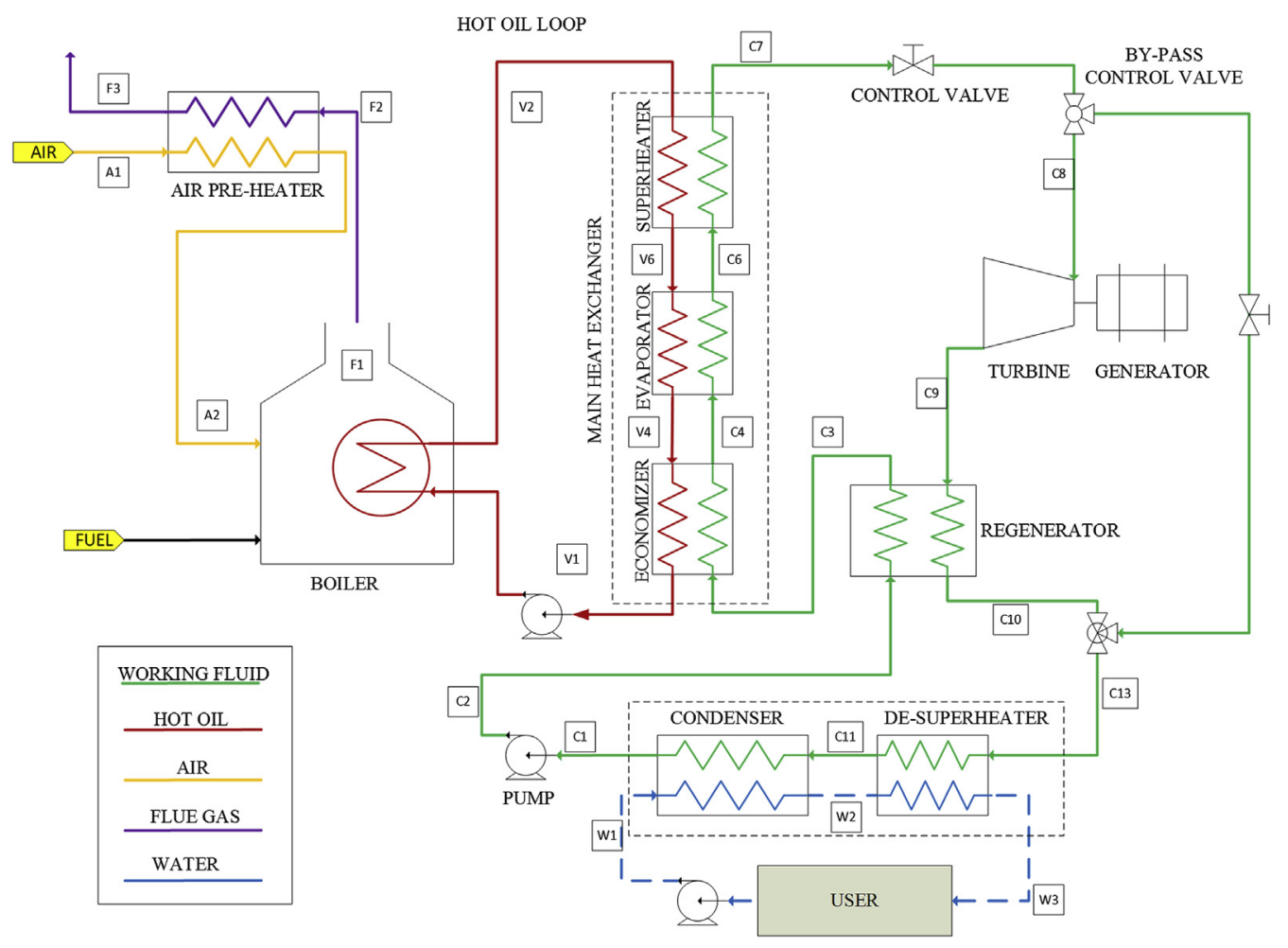

Fig. 1. Scheme of the ORC plant considered in this study.

heat selling prices, thermal power required by the heat user, fuel cost) and the results of the design optimization algorithm (i.e., the sizes and performance features of the equipment units, the heat transfer area of heat exchangers, the heat transfer coefficients of streams at design load, pressures, temperatures and mass flow rates at design load).

The variables of the part-load optimization model $\boldsymbol{x}_{0, t}$ are the temperatures $T$, pressures $p$ and mass flow rates $\dot{m}$ of all the streams (turbine admission, bypass stream, hot oil loop, water loop, and boiler fuel, air and flue gases), the pressure drop of the turbine admission valve, heat transfer areas of the main heat exchanger sections (economizer, evaporator and superheater) and condenser sections (de-superheating and condensation) during time period $t$. The objective function of the part-load optimization problem may be any performance index relevant for the plant operator. For example, it could be the net electric efficiency of the cycle or the gross margin $G M_{\mathrm{t}}$ of the plant at the operating period $t$ :

$$
\begin{aligned}
G M_{\mathrm{t}}= & {\left[s p_{\mathrm{EL}} \dot{W}_{\mathrm{EL}, \mathrm{t}}+s p_{\mathrm{Q}} \dot{Q}_{\mathrm{USER}, \mathrm{t}}\right.} \\
& \left.-p c_{\mathrm{FUEL}} \dot{m}_{\mathrm{FUEL}, \mathrm{t}} L H V_{\mathrm{FUEL}}\right] \Delta t_{\mathrm{t}}
\end{aligned}
$$

where $p c_{\mathrm{FUEL}}$ denotes the fuel specific purchase cost, $L H V_{\mathrm{FUEL}}$ is the fuel lower heating value, $s p_{\mathrm{EL}}$ is the electricity selling price, $\dot{W}_{\mathrm{EL}, \mathrm{t}}$ is the net electric power, $s p_{\mathrm{Q}}$ is the heat selling price and $\Delta t_{t}$ the duration of period $t$.

The model equations are handled as constraints of the optimization problem. A summary of such constraints is reported below.

\subsubsection{Constraints/equations related to the cycle model}

1) Energy and mass balance equations of each equipment unit (economizer, evaporator, superheater, turbine, regenerator, pump, condenser, water loop, heat user, turbine admission valve, bypass mixer and splitter) under steady-state flow (transients and system dynamics are not considered).

2) Heat transfer rate equation of each heat exchanger $i$,

$\dot{Q}_{\mathrm{i}, \mathrm{t}}=S_{\mathrm{i}} U_{\mathrm{i}, \mathrm{t}} \Delta T_{\mathrm{ml}, \mathrm{i}, \mathrm{t}}$,

where $\dot{Q}_{i, t}$ denotes the exchanged thermal power, $S_{i}$ the heat transfer area, $U_{\mathrm{i}, \mathrm{t}}$ the overall heat transfer coefficient (depending on the current mass flow rates as described below), and $\Delta T_{\mathrm{ml}, \mathrm{i}, \mathrm{t}}$ the average logarithmic temperature difference between hot and cold flows.

3) Simplified correlations to relate the heat transfer coefficients to the fluid mass flow rates across the heat exchanger,

$U_{\mathrm{i}, \mathrm{t}}=U_{\mathrm{i}, \mathrm{D}} \cdot\left(\frac{\dot{m}_{\mathrm{L}, \mathrm{t}}}{\dot{m}_{\mathrm{L}, \mathrm{D}}}\right)^{\tau_{\mathrm{i}}}$

where $U_{\mathrm{i}, \mathrm{D}}$ denotes the nominal (in design conditions) overall heat transfer coefficient of heat exchanger $i, \dot{m}_{\mathrm{L} . \mathrm{D}}$ denotes the nominal mass flow rate of the fluid with the lowest heat transfer coefficient (i.e., the one which actually limits the heat transfer rate), $\dot{m}_{\mathrm{L}, \mathrm{t}}$ is the mass flow rate of the fluid at time period $t$, and $\tau_{\mathrm{i}}$ is a calibration parameter depending on the type of fluid ( 0.58 for liquid, 0.52 for two-phase, 0.63 for vapor/gas). The values of $\tau_{\mathrm{i}}$ have been determined by regressing off-design calculations performed with Thermoflex (a commercial software capable of performing accurate design and off-design simulations of power plants [24]) for different power cycles.

4) Simplified correlations to relate the pressure drop across each heat exchangers to the fluid mass flow rate: 
$\Delta p_{\mathrm{i}, \mathrm{t}}=\Delta p_{\mathrm{i}, \mathrm{D}} \cdot\left(\frac{\dot{m}_{\mathrm{t}}}{\dot{m}_{\mathrm{D}}}\right)^{2}$

where $\Delta p_{\mathrm{i}}(t)$ denotes the nominal (in design conditions) pressure drop of the $i$-th heat exchanger, $\dot{m}_{0}$ denotes the nominal mass flow rate of the flow, and $\dot{m}_{\mathrm{t}}$ is the mass flow rate at time period $t$.

5) Total heat transfer area of the main heat exchanger and condenser. The model assumes that the main heat exchanger (ideally divided into three sections: economizer, evaporator and superheater) is once-through, as in many ORC plants. Thus, the extensions of the sections can vary depending on the operative conditions and fluid flow rate. Thus, a constraint on the total area of the three sections must be set:

$S_{\mathrm{ECO}, \mathrm{t}}+S_{\mathrm{EVA}, \mathrm{t}}+S_{\mathrm{SH}, \mathrm{t}}=S_{\mathrm{MHE}}$

where $S_{\mathrm{MHE}}$ is the overall heat transfer area computed at the design stage, while $S_{\mathrm{ECO}, \mathrm{t}}, S_{\mathrm{EVA}, \mathrm{t}}, S_{\mathrm{SH}, \mathrm{t}}$ are the heat transfer areas of economizer, evaporator and superheater during time period $t$.

A similar constraint is written for the condenser total area (divided into desuperheating section and condensation section).

6) Turbine overall characteristic law relating the non-dimensional flow rate $\varphi_{\mathrm{t}}$ to the expansion pressure ratio $\beta_{\mathrm{T}, \mathrm{t}}$ of the turbine according to the Stodola's law [9]:

$\varphi_{\mathrm{t}}=f_{\text {Stodola }}\left(\beta_{\mathrm{T}, \mathrm{t}}\right)$

where

$\varphi_{\mathrm{t}}=\frac{\dot{m}_{\mathrm{C} 8, \mathrm{t}} \sqrt{\gamma R T_{\mathrm{C} 8, \mathrm{t}} z_{\mathrm{C} 8, \mathrm{t}}}}{p_{\mathrm{C} 8, \mathrm{t}} A_{\mathrm{T}}}$,

and $f_{\text {Stodola }}$ denotes the Stodola's law relation. In Eq. (8) $\gamma$ denotes the ratio between constant pressure and constant volume specific heat capacity of the fluid, $R$ is the ideal gas constant, $A_{\mathrm{T}}$ is a reference turbine area (e.g., cross-sectional area), while $z_{c 8, t}$ is the compressibility factor (which has been added to take into account of the real gas effect of the fluid [4]) evaluated at the turbine inlet conditions.

7) The turbine performance map which provides the turbine isentropic efficiency as a function of its operative variables. The correlation derived in Ref. [8], one of the few ones publicly available, has been considered. It relates the turbine isentropic efficiency to the relative variations of volumetric flow ratio and the turbine enthalpy drop:

$\eta_{\mathrm{ISO}, \mathrm{T}, \mathrm{t}}=\eta_{\mathrm{ISO}, \mathrm{T}, \mathrm{D}} \cdot r_{\mathrm{H}, \mathrm{t}} \cdot r_{\mathrm{V}, \mathrm{t}}$

where $r_{\mathrm{H}, \mathrm{t}}$ and $r_{\mathrm{V}, \mathrm{t}}$ are computed with the following formula,

$r_{\mathrm{H}, \mathrm{t}}=\left(\left(a_{1} \cdot r_{\mathrm{T}, \mathrm{t}}+a_{2}\right) \cdot r_{\mathrm{T}} a_{3}\right) \cdot r_{\mathrm{T}, \mathrm{t}}+a_{4}$,

$r_{\mathrm{V}, \mathrm{t}}=\left(\left(\left(a_{5} \cdot r_{\mathrm{VT}, \mathrm{t}}+a_{6}\right) \cdot r_{\mathrm{VT}}-a_{7}\right) \cdot r_{\mathrm{VT}, \mathrm{t}}+a_{8}\right) \cdot r_{\mathrm{VT}, \mathrm{t}}+a_{9}$.

The parameters referred to in Eqs. (10) and (11) are reported in Table 1 while $r_{\mathrm{T}}$ and $r_{\mathrm{VT}}$ (relative variations of the turbine enthalpy drop and outlet volumetric flow rate) are defined in Eqs. (12) and (13):
$r_{\mathrm{T}, \mathrm{t}}=\sqrt{\left(\Delta h_{\mathrm{T}, \mathrm{t}} / \Delta h_{\mathrm{T}, \mathrm{D}}\right)}$,

$r_{\mathrm{VT}, \mathrm{t}}=\sqrt{\left(\dot{V}_{\mathrm{T}, \mathrm{t}} / \dot{V}_{\mathrm{T}, \mathrm{D}}\right)}$,

where $\Delta h_{\mathrm{T}, \mathrm{D}}$ and $\dot{V}_{\mathrm{T}, \mathrm{D}}$ are the design values of respectively the turbine enthalpy drop and the turbine outlet volumetric flow rate, while $\Delta h_{\mathrm{T}, \mathrm{t}}$ and $\dot{V}_{\mathrm{T}, \mathrm{t}}$ are their values during time period $t$.

A 3-D plot of the turbine isentropic efficiency is reported in Fig. 2.

We have to notice a typo in the parameters of the equations of the original publication: according to Eq. (11) in Ref. [8], the correction parameter $\left(r_{\mathrm{H}, \mathrm{t}} \cdot r_{\mathrm{V}, \mathrm{t}}\right)$ would not be equal to 1.0 at the nominal conditions. The correct parameters should be those reported in Table 1 .

8) Inequality constraint to avoid premature evaporation in the regenerator. This constraint is particularly important for the sliding pressure mode at low ORC loads, when the regenerator heat transfer area is large compared to the fluid mass flow rate and the fluid pressure is low. The constraint guarantees that the liquid temperature at the outlet of the regenerator $T_{\mathrm{C} 3, \mathrm{t}}$ is $\Delta T_{\text {MARG }}$ lower than the saturation temperature $T_{\text {EVA,t }}$ (where $\Delta T_{\text {MARG }}$ is a safety margin temperature difference):

$T_{\mathrm{C} 3, \mathrm{t}} \leq T_{\mathrm{EVA}, \mathrm{t}}-\Delta T_{\mathrm{MARG}}$

A $\Delta T_{\text {MARG }}$ of $5{ }^{\circ} \mathrm{C}$ is considered in the following analysis.

9) Inequality constraint to satisfy the user's heat demand at each time period $t$ :

$\dot{Q}_{\text {COND }} \geq \dot{Q}_{\text {USER,t }}$.

10) Non-negativity constraints on the mass flow rates, and bound constraints on pressures and temperatures (to guarantee the physical feasibility of the solution).

11) Equality constraints imposing the thermodynamic relations between fluid properties (i.e., specific volume, enthalpy and entropy as functions of pressure and temperature) of each stream. REFPROP [25], a commercial software using properly calibrated equations for the thermodynamic and transport properties of a wide variety of pure fluids and mixtures. The equations of state proposed in Refs. [26,27] are used for MDM and toluene respectively.

Table 1

Parameters required for the computation of the isentropic part load efficiency of the expander.

\begin{tabular}{lc}
\hline Parameter & Value \\
\hline $\mathrm{a}_{1}$ & 1.398 \\
$\mathrm{a}_{2}$ & -5.425 \\
$\mathrm{a}_{3}$ & 6.724 \\
$\mathrm{a}_{4}$ & 0.619 \\
$\mathrm{a}_{5}$ & -0.21 \\
$\mathrm{a}_{6}$ & 1.117 \\
$\mathrm{a}_{7}$ & -2.533 \\
$\mathrm{a}_{8}$ & 2.588 \\
$\mathrm{a}_{9}$ & 0.038 \\
\hline
\end{tabular}




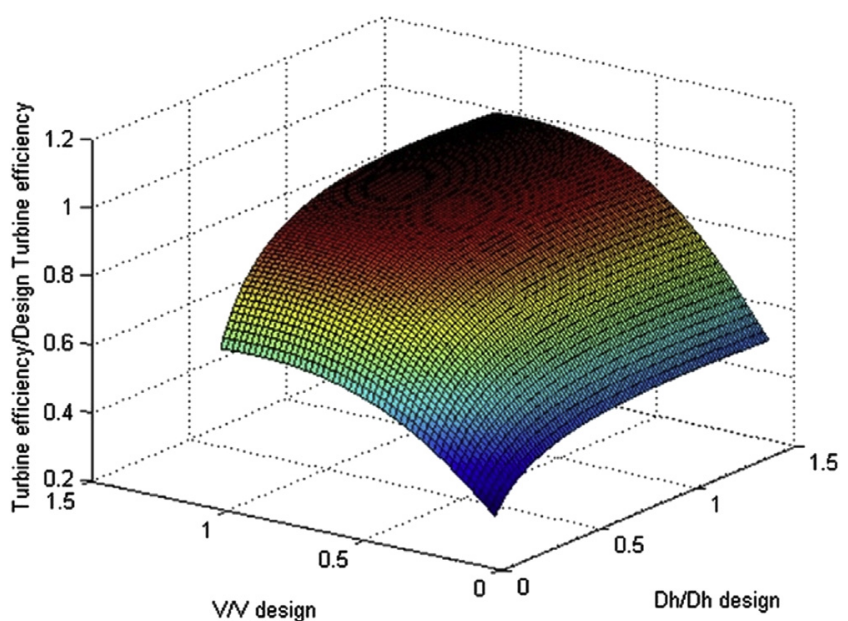

Fig. 2. Turbine efficiency in off-design operation as function of the volume ratio $r_{\mathrm{VT}}$ and enthalpy drop ratio $r_{\mathrm{T}}$

\subsubsection{Constraints/equations related to the boiler model}

1) Energy and mass balance equations of the boiler furnace assuming complete combustion of fuel species, no direct radiation to heat exchangers, and heat losses equal to $3 \%$ of the fuel thermal power (LHV basis). It is also assumed that the percent excess air is kept constant at part-load operation, equal to the design value (80\%). The energy and mass balance equations of the boiler furnace relate the fuel flow rate and preheated air temperature to the flow rates of air and flue gases, and flue gas temperature.

2) Energy and mass balance equations of the air preheater and radiative heat exchanger (flue gases-oil).

3) Heat transfer rate equation of the air preheater and radiative heat exchanger (flue gaes-oil), as in Eq. (3).

4) Simplified correlations relating heat transfer coefficients and pressure drops to the fluid mass flow rates across each heat exchanger, as in Eq. (5).

5) Equation of state and thermodynamic property equations of air and flue gases (modeled as ideal mixtures of ideal gases) and oil (modeled as uncompressible liquid with constant specific heat capacity).

\subsubsection{Part-load optimization problem}

The part-load optimization problem aims at maximizing the gross margin of each operating period $t$. It can be formally stated as follows,

$$
\begin{aligned}
& \max _{\boldsymbol{x}_{\mathrm{O}, \mathrm{t}}} G M_{\mathrm{t}}\left(\boldsymbol{x}_{\mathrm{D}}, \boldsymbol{x}_{\mathrm{O}, \mathrm{t}}\right) \\
& \text { s.t. } \boldsymbol{g}_{\mathrm{O}}\left(\boldsymbol{x}_{\mathrm{D}}, \boldsymbol{x}_{\mathrm{O}, \mathrm{t}}\right) \leq 0 \\
& \boldsymbol{h}_{\mathrm{O}}\left(\boldsymbol{x}_{\mathrm{D}}, \boldsymbol{x}_{\mathrm{O}, \mathrm{t}}\right)=0 \\
& \boldsymbol{l} \boldsymbol{b}_{\mathrm{O}} \leq \boldsymbol{x}_{\mathrm{O}, \mathrm{t}} \leq \boldsymbol{u} \boldsymbol{b}_{\mathrm{O}} \\
& \boldsymbol{x}_{\mathrm{O}, \mathrm{t}} \in \mathscr{R}^{\mathrm{t}}
\end{aligned}
$$

where the objective is to maximize the gross margin $G M_{\mathrm{t}}$ of time period $t$ which depends on the cycle design variables $\boldsymbol{x}_{\mathrm{D}}$ (size of the plant, turbine design variables, cycle design variables, etc) and operating variables $\boldsymbol{x}_{\mathrm{O}, \mathrm{t}}$ (pressures, temperatures, mass flow rates, heat transfer surfaces of the variable sections within the main heat exchanger and condenser) at time period $t$. In (P1) $\boldsymbol{l b}_{\mathrm{O}}$ and $\boldsymbol{u} \boldsymbol{b}_{\mathrm{O}}$ denote the lower and upper bounds on the operating variables (due to physical limitations), while $\boldsymbol{g}_{0}$ and $\boldsymbol{h}_{0}$ denote respectively the set of inequality and equality constraints corresponding to the model equations of both cycle and boiler. Note that in the part-load operation problem the design of the cycle is not changed but it is fixed (hence $\boldsymbol{x}_{\mathrm{D}}$ are kept constant).

The optimization problem features 31 variables (size of vector $\boldsymbol{x}_{\mathrm{O}, \mathrm{t}}$ ), 25 equality constraints (size of $\boldsymbol{h}_{\mathrm{O}}$ ) and 20 inequality constraints (size of $\mathbf{g}_{0}$ ). The difference between number of variables and constraints, six, is equal to the number of independent control variables which can be adjusted to control the plant load. Although not relevant for the above-described optimization problem (as they are handled as the other variables, without any distinction), it is worth identifying such independent variables to analyze the results of the optimization. Among the possible choices, we consider as independent control variables the following ones: working fluid flow rate $\dot{m}_{\mathrm{C}}$, hot oil flow rate $\dot{m}_{\mathrm{V}}$, water flow rate $\dot{m}_{\mathrm{W}}$, by-pass stream flow rate $\dot{m}_{\mathrm{BP}}$, throttling valve pressure drop $\left(p_{\mathrm{C} 7}-p_{\mathrm{C} 8}\right)$, hot water temperature $T_{\mathrm{w} 3}$.

Since the objective function as well as most of the constraints are nonlinear and nonconvex with respect to the optimization variables, the optimization problem is a nonconvex NonLinear Program (NLP).

\subsection{Optimization algorithm}

The model equations and related optimization problem have been coded in Matlab [28]. Although commercially available process simulation codes could easily perform the off-design calculation of ORCs (see for instance [8]), we preferred to develop a Matlab code for the following advantages:

- plenty of optimization algorithms for constrained nonlinear optimization problems (several versions of sequential quadratic programming, interior point methods, Augmented Lagrangian algorithms, etc) are available in Matlab and it is straightforward to test them and pick up the best one for the specific application;

- having access to each single equation, it is possible to reduce the difficulty of the optimization problem by performing a direct substitution of variables (eliminating variables and equations by direct substitution the complexity of the optimization problem decreases);

- it is possible to properly scale (normalize) each equation and variable so as to limit the numerical issues of the optimization algorithm;

- it is possible to repeat the optimization starting from different initial points with the aim of minimizing the risk of converging to a local optimum.

After a preliminary comparison of algorithms, the SQP (Sequential Quadratic Programming) available in the Matlab Optimization Toolbox [13] has been selected. As function derivatives (objective and constraints) cannot be analytically computed, gradient are estimated as finite differences, and the Hessian is estimated with the Quasi-Newton BFGS method. The preliminary computational tests have confirmed the superiority of SQP algorithms on highly constrained NLPs, as observed in Ref. [29].

\subsection{Part-load model validation}

The cycle model described in part A of this two part paper has been validated with the data of a real plant, the "Scharnhauser Park" biomass-fired CHP plant in Ostfildern (Germany), available in Refs. [30,31]. The plant scheme is similar to that reported in Fig. 3. It features a superheated regenerative ORC with MDM as working fluid, 5.3 MW thermal output and $1 \mathrm{MW}$ nominal power output. Design parameters as well as the part-load control strategy 


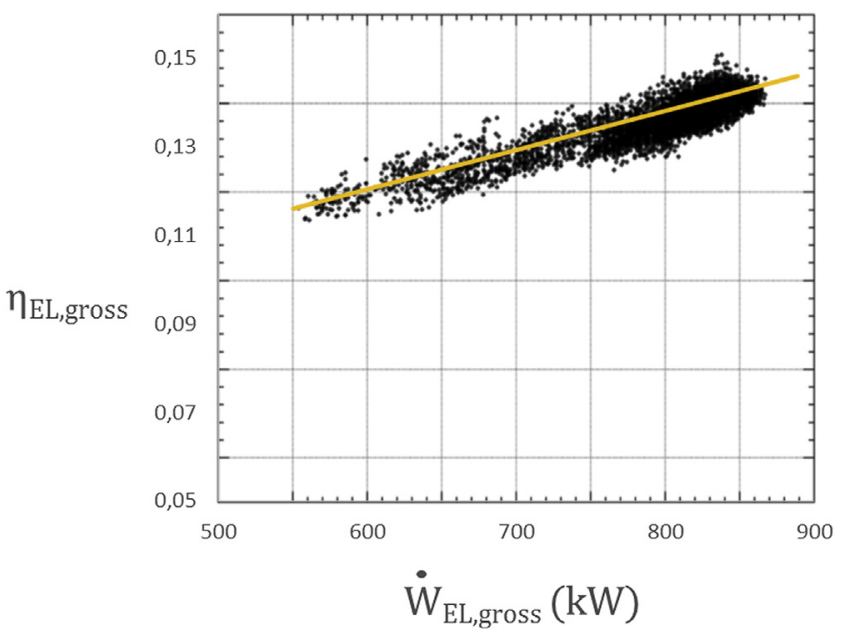

Fig. 3. Comparison of the trend of gross electric efficiency versus gross turbine power output for a set of experimental data of the "Scharnhauser Park" ORC plant [30,31] and the results obtained from the part-load model presented in this paper and tuned to follow the control strategy of the plant.

(sliding-pressure) of the "Scharnhauser Park" plant needed for the comparison were taken from Refs. [30,31]. Components and equipment of the cycle have been sized to obtain the same cycle design as the "Scharnhauser Park" plant (see Part A [1]). Then, six additional constraints have been added to the part-load model so as to force the sliding-pressure control strategy followed by the real plant. Important details were kindly communicated by the corresponding author of $[30,31]$. Due to the addition of the six constraints, the part-load optimization problem was in fact turned into a system of nonlinear equations simulating the behavior of the real plant.

The comparison with the experimental measurements available in Refs. $[30,31]$ is shown in Figs. (3) and (4). Fig. 3 compares the measured data of gross turbine power and gross cycle electric efficiency (turbine gross electric power divided by the cycle thermal input) with the results obtained from the part-load model. In Fig. 4 the measurements of turbine inlet pressure and volumetric flow rate of working fluid at pump inlet are compared with the results of the part-load model. Figs. (3) and (4) indicate that the part-load model can accurately predict the performance and part-load

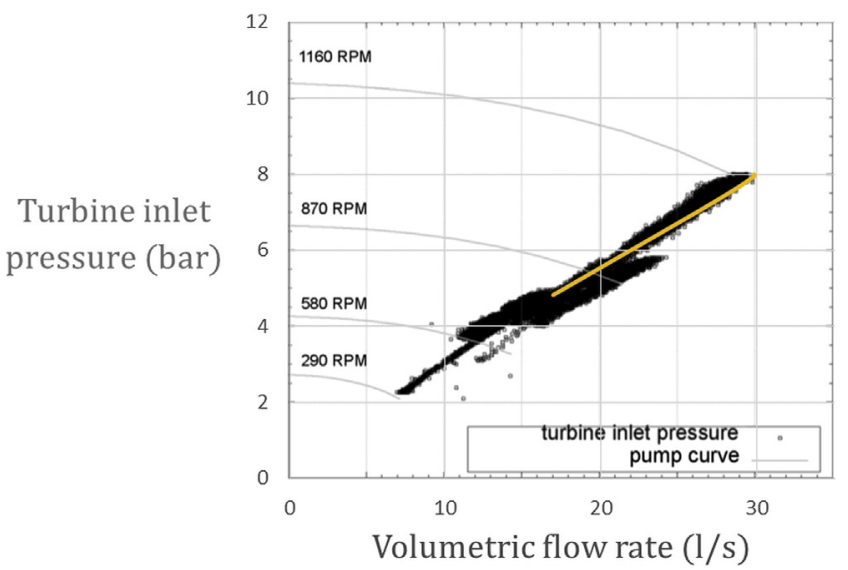

Fig. 4. Comparison between the data of turbine inlet pressure versus volumetric flow rate measured at the "Scharnhauser Park" ORC plant [30,31] and the results obtained from the part-load model presented in this paper. These points are obtained for the different load levels shown in Fig. 3. operation of the real CHP cycle over a sufficiently wide range of loads.

As far as the boiler is concerned, it was not possible to validate its model because (i) the structure of the boiler of the "Scharnhauser Park" power plant differs from the one considered here (the boiler of the "Scharnhauser Park" power plant features also a heat exchanger transferring heat directly from flue gases to the district heating network), and (ii) the part-load control strategy of the boiler cannot be reproduced with the measurements reported in Refs. [30,31]. Thus, we have thoroughly checked the consistency of the model results on the basis of engineering criteria and comparisons with the part-load behavior of industrial boilers.

\subsection{Maximum-efficiency part-load operation of ORCs}

In this section the part-load model and algorithm are tested on the ORC plants optimized in Part A [1] for maximum electric efficiency so as to evaluate the performance of the SQP algorithm (computational time and convergence issues), and analyze the optimal control strategy for such plants. Their part-load operation strategy leading to the maximum electric efficiency is determined for a wide range of loads, ranging from $100 \%$ (nominal value) to $20 \%$ of condenser thermal power. A load step of $85 \mathrm{~kW}$ is considered so as to plot the main operative variables as functions of the load. As a result, 51 load levels have been optimized for each design. In order to save computational time and minimize the risk of converging to a local optimum, it was decided to optimize the 51 load levels in descending order (starting from the $100 \%$ load case). The $100 \%$ load solution, which is the design point (already known), is used as starting point of the $100 \%$ load operating point. Once the first load is computed, the process is repeated by using such solution as start-ing point for the next lower load point. A thorough analysis of the optimized solutions indicates that SQP likely converges to globally optimal solutions.

As far as the computational time is concerned, optimizing 50 part-load conditions takes $60 \mathrm{~s}$ (about $1.3 \mathrm{~s}$ for each load condition) on an Intel Xeon $2.8 \mathrm{GHz}$ 12-core computer without exploiting parallel computing for the calculation of the finite differences.

Fig. 5 reports the plot of the electric and thermal efficiency of design PR-140 with toluene described in Part A [1] when operated at part-load following the optimal control strategy determined by the part-load model for maximum efficiency. On the basis of the plot of Fig. 6 showing the evaporation and turbine admission pressures as functions of the condenser thermal load, it is clear that the optimal control strategy follows the sliding-pressure mode in the high range of loads (from $100 \%$ to $50 \%$ of the condenser thermal power), and a combination of sliding-pressure and throttling in the range of low loads (below 50\%). The pressure loss of the throttling valve is indeed zero in the high load range as the turbine admission pressure is essentially equal to the evaporation pressure. In the low load range, the plain sliding-pressure control strategy cannot be applied as the evaporation pressure would be so low that evaporation would begin in the regenerator causing severe problems of vibrations and an unsteady flow to the evaporator. For this reason, at low loads, the optimized control strategy is hybrid: it decreases the evaporation pressure and partially closes the throttling valve at the turbine admission to further decrease the fluid mass flow rate and the cycle load.

Fig. 7 details the comparison between the net electric efficiency of the optimized control-strategy and that of the conventional modes (sliding-pressure and throttling). The figure shows that (1) the throttling control mode is the least efficient one over the whole range of loads, and (2) in the range 100-33\%, the optimized control strategy achieves essentially the same net electric efficiency of the ORC as the sliding-pressure control mode. Below about $33 \%$ of load, 


\section{Design PR-140 with toluene}

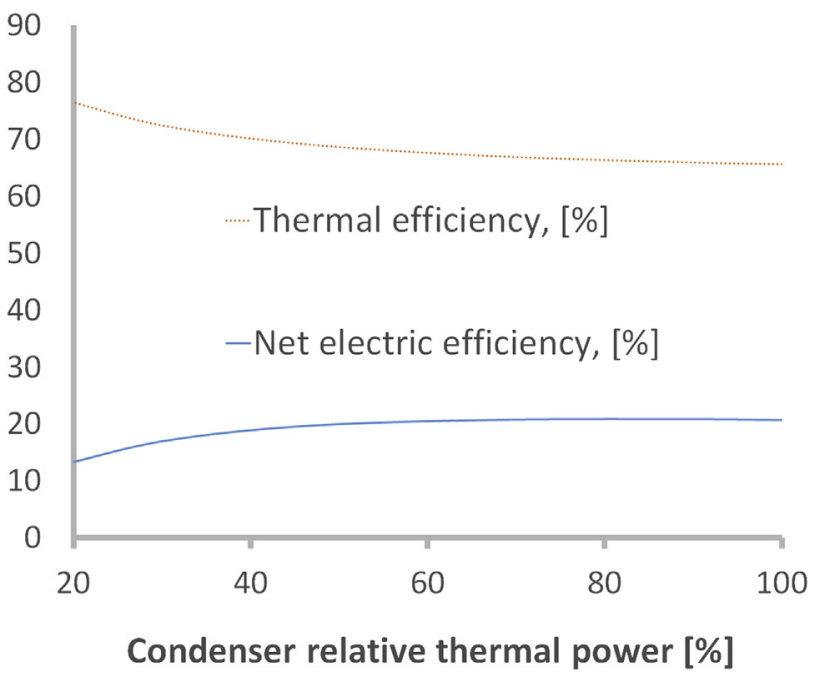

Fig. 5. Plot of the net electric efficiency and thermal efficiency of design "PR-140" using toluene (described in Part A [1]) with respect to the condenser relative thermal load (thermal power/design thermal power of the condenser).

the plain sliding-pressure control strategy cannot be applied while the optimized control strategy (using also the turbine admission valve) can.

Fig. 8 shows how the independent control variables are adjusted in the control strategy of plant PR-140 optimized for maximum efficiency. Only five independent control variables are plotted (working fluid flow rate, oil flow rate, water flow rate, throttling valve pressure drop, hot water temperature) because the sixth one, the by-pass flow rate, is always equal to zero.

It is important to note that similar optimized part-load operation strategies and computational times for the convergence of the SQP algorithm have been found for design PR-110 with toluene and designs PR-140 and PR-110 with MDM. Instead, the part-load operation strategy of designs PR-80 are worth analyzing since

\section{Design PR-140 with toluene}

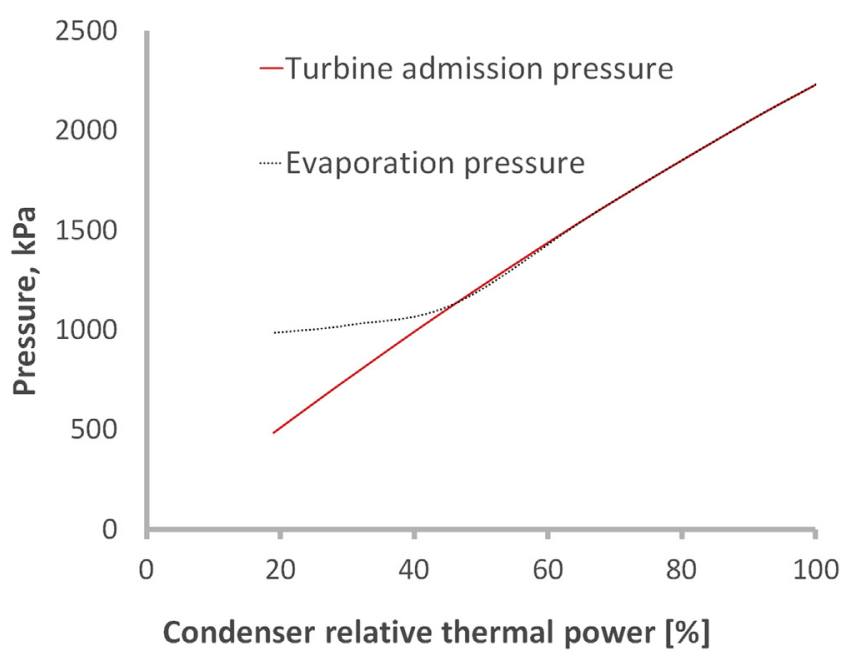

Fig. 6. Plot of the evaporation and turbine admission pressures of design "PR-140" using toluene (described in Part A [1]) with respect to the condenser relative thermal load (thermal power/design thermal power of the condenser).

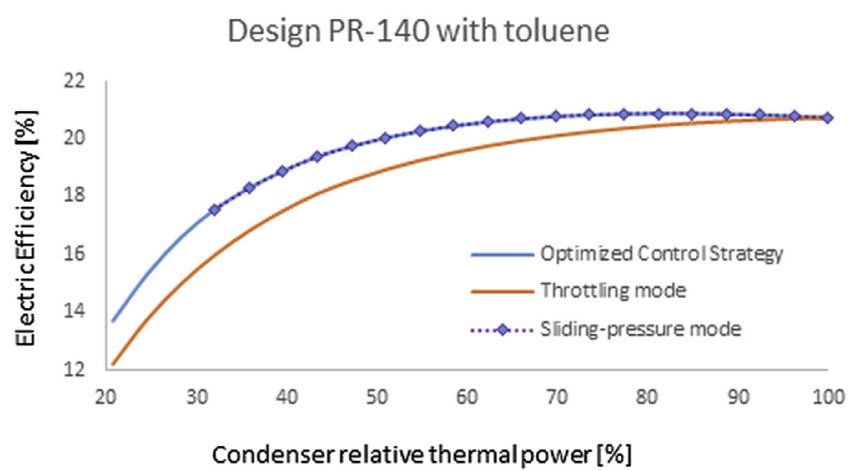

Fig. 7. Comparison between the net electric efficiency of the optimized control-strategy and that of the conventional modes (sliding-pressure and throttling) as a function of the condenser relative thermal load.

they are quite different. Fig. 9 plots the net electric efficiency and the thermal efficiency of design PR-80 with toluene as functions of the condenser relative load. Fig. 10 shows the plot of evaporation pressure and the turbine admission pressure as functions of the condenser load. As the heat demand decreases, the slidingpressure control mode is adopted until the $70 \%$ load is reached. Then, the evaporation pressure changes trend: the evaporation pressure is increased as the load decreases. This is quite peculiar compared to the typical load-control strategies of conventional power plants. The analysis of the temperatures of the cycle streams reveals that this happens in order to avoid the premature evaporation of liquid in the regenerator.

\section{Simultaneous optimization of design and part-load operation}

Optimizing the design first and the part-load operation then could lead to suboptimal solutions, as justified in the introduction.

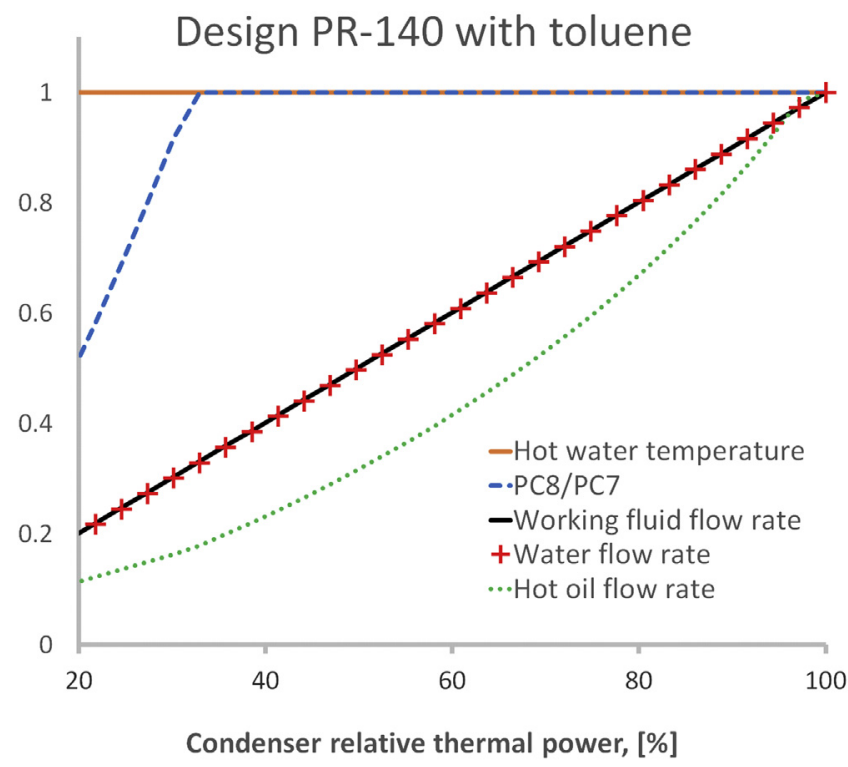

Fig. 8. Plot of the independent control variables as a function of the condenser relative load relative to the maximum-efficiency part-load control strategy of design PR 140 with toluene. Working fluid flow rate, hot oil flow rate and hot water temperature are normalized with respect to their design (full-load) values, while $\mathrm{p}_{\mathrm{C} 8} / \mathrm{p}_{\mathrm{C} 7}$ denotes the pressure ratio of the turbine admission valve (if equal to one, the valve pressure drop is zero). 


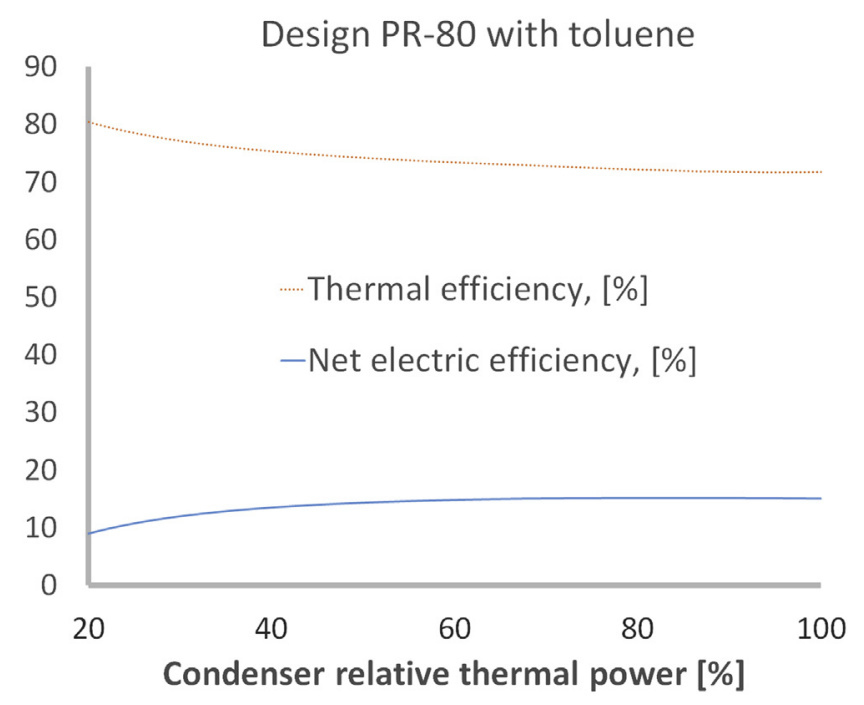

Fig. 9. Net electric efficiency and the thermal efficiency of design PR-80 with toluene as a function of the condenser load.

In theory, both design and part-load operation variables (and strategy) should be optimized all at once. Solving such a simultaneous optimization problem would allow to determine the values of both design variables $\boldsymbol{x}_{\mathrm{D}}$ and operating variables $\boldsymbol{x}_{0, \mathrm{t}}$ for each expected operating time period of the year.

\subsection{Optimization problem}

The problem can be stated as follows:

$$
\begin{aligned}
& \max _{\boldsymbol{x}_{\mathrm{D}}, \boldsymbol{x}_{\mathrm{O}, \mathrm{t}}} P\left(\boldsymbol{x}_{\mathrm{D}}, \boldsymbol{x}_{\mathrm{O}, \mathrm{t}}\right) \\
& \text { s.t. } \boldsymbol{g}_{\mathrm{D}}\left(\boldsymbol{x}_{\mathrm{D}}\right) \leq 0 \\
& \boldsymbol{g}_{\mathrm{O}}\left(\boldsymbol{x}_{\mathrm{D}}, \boldsymbol{x}_{\mathrm{O}, \mathrm{t}}\right) \leq 0 \\
& \boldsymbol{h}_{\mathrm{O}}\left(\boldsymbol{x}_{\mathrm{D}}, \boldsymbol{x}_{\mathrm{O}, \mathrm{t}}\right)=0 \\
& \boldsymbol{l b}_{\mathrm{D}} \leq \boldsymbol{x}_{\mathrm{D}} \leq \boldsymbol{u} \boldsymbol{b}_{\mathrm{D}} \\
& \boldsymbol{l b}_{\mathrm{O}} \leq \boldsymbol{x}_{\mathrm{O}, \mathrm{t}} \leq \boldsymbol{u} \boldsymbol{b}_{\mathrm{O}} \\
& \boldsymbol{x}_{\mathrm{D}} \in \mathscr{R}^{\mathrm{n}_{\mathrm{D}}} \\
& \boldsymbol{x}_{\mathrm{O}}(\mathrm{t}) \in \mathscr{R}^{\mathrm{n}_{\mathrm{O}}}
\end{aligned}
$$

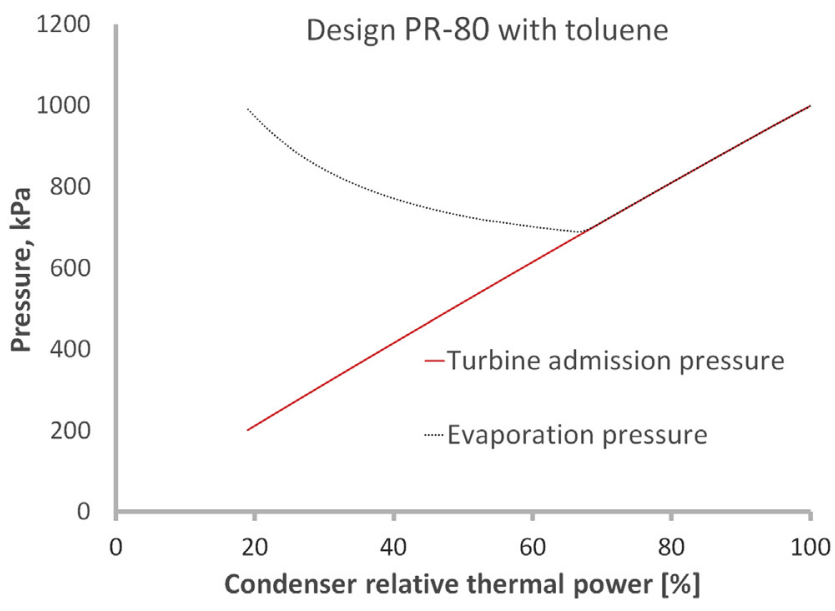

Fig. 10. Plot of the evaporation and turbine admission pressures of design PR-80 using toluene (described in Part A [1]) with respect to the condenser relative thermal load (thermal power/design thermal power of the condenser). where $\boldsymbol{x}_{\mathrm{D}}, \boldsymbol{l} \boldsymbol{b}_{\mathrm{D}}, \boldsymbol{u} \boldsymbol{b}_{\mathrm{D}}$ and $\boldsymbol{g}_{\mathrm{D}}$ label respectively the set of design variables (plant size, evaporation design pressure, condenser design pressure, design superheating degree, design pinch point temperature difference of regenerator, main heat exchanger, turbine rotational speed, and expansion ratio of each turbine stage), lower and upper bounds on the design variables and design constraints (see Part A [1]). Instead $\boldsymbol{x}_{0, t}, \boldsymbol{l} \boldsymbol{b}_{\mathrm{O}}, \boldsymbol{u} \boldsymbol{b}_{\mathrm{O}}, \boldsymbol{h}_{\mathrm{O}}$, and $\boldsymbol{g}_{\mathrm{O}}$ concern the partload operation. $P$ denotes the annual profit of the plant and it depends on both design and operating variables:

$$
\begin{aligned}
P\left(\boldsymbol{x}_{\mathrm{D}}, \boldsymbol{x}_{\mathrm{O}, \mathrm{t}}\right)= & \sum_{t \in \Theta} G M_{\mathrm{t}}\left(\boldsymbol{x}_{\mathrm{D}}, \boldsymbol{x}_{\mathrm{O}, \mathrm{t}}\right)-\left(C_{\mathrm{B}}\left(\boldsymbol{x}_{\mathrm{D}}\right)+C_{\mathrm{P}}\left(\boldsymbol{x}_{\mathrm{D}}\right)\right. \\
& \left.+\sum_{j \in \Phi} C_{\mathrm{j}}\left(\boldsymbol{x}_{\mathrm{D}}\right)\right) \cdot L C C R-C_{\mathrm{M}}\left(\boldsymbol{x}_{\mathrm{D}}\right),
\end{aligned}
$$

where $G M_{\mathrm{t}}$ is the gross profit of operating period $t$ (depending on both design and operating variables), $\Theta$ is the set of expected operating periods of the year, $C_{B}$ is the cost of civil works, contingencies, engineering and procurement, $C_{P}$ is the cost of permits, $C_{M}$ is the fixed operation and maintenance cost, $C_{\mathrm{j}}$ is the investment cost of the $j$-th equipment unit (boiler, turbine, etc) and $\Phi$ is the set of equipment units of the cycle. It is worth noting that $C_{\mathrm{B}}, C_{\mathrm{P}}, C_{\mathrm{M}}$ and $C_{\mathrm{j}}$ depend only on the design variables $\boldsymbol{x}_{\mathrm{D}}$. The LCCR allows to convert the investment cost into an annual cost. Indeed it is defined as the amount of revenue per unit of investment cost that is needed to pay the carrying charges on that investment (return on investment, income and property tax, book depreciation, and insurance) [32].

As far as the design variables are concerned, it is important to note that not only those considered in Part A [1] (evaporation pressure $p_{\mathrm{EVA}}$, condensation pressure $p_{\mathrm{COND}}$, superheating degree $\Delta T_{\mathrm{SH}}$, regenerator pinch point temperature difference $\Delta T_{\mathrm{PP}, \mathrm{REG}}$, main heat exchanger temperature difference $\Delta T_{\mathrm{PP}, \mathrm{MHE}}$, turbine rational speed $\omega$, number of stages and expansion ratios of turbine stage $\beta_{\mathrm{i}}$ ), but also the plant size is optimized. Indeed, depending on the economic data, heat demand duration curve and part-load performance maps of the plant, it may be profitable to oversize or undersize the plant with respect to the nominal heat load demand.

Tackling Problem (P2) is quite challenging because (i) the relatively large number of variables and constraints, (ii) the optimization algorithm may converge to a local optimum because of the nonconvexity of the objective function and constraints, (iii) the cycle design model and turbine design algorithm described in Part A [1] (required to compute the plant investment costs $C_{B}, C_{P}, C_{M}$ and $C_{\mathrm{j}}$ within the objective function) are non-differentiable and discontinuous black-box functions (as shown in Part A) which would jeopardize the use of efficient gradient-based optimization algorithms. For these reasons, solving Problem (P2) is really computationally expensive and may return very poor solutions.

\subsection{Two-level decomposition}

In order to overcome these issues, it was decided to perform a two-level decomposition of the problem by optimizing the design variables at the upper level and, for each fixed set of design variables, optimize the part-load operation for each expected operating period of the year. The corresponding two-level algorithm is shown in Fig. 11. At the upper level, the black-box optimization algorithm PGS-COM [2] varies the design variables $\boldsymbol{x}_{\mathrm{D}}$ looking for the solution with maximum annual profit. For each design solution $\boldsymbol{x}_{\mathrm{D}}$ sampled by PGS-COM, first cycle and turbine are designed and their investment costs are assessed with the Matlab routine descried in Part A [1], then the plant part-load operation problem (P1) is 
optimized with the SQP algorithm for each expected operating periods of the year. The part-load problem (P1) returns the gross margin GM gained by the plant, the optimal control strategy and the values of the operating variables in each expected operating periods. At this point, the annual profit can be computed with Eq. (16) and its value is returned to the upper-level optimizer, PGSCOM, which uses such information to proceed and determine the next point $\boldsymbol{x}_{\mathrm{D}}$ to sample (further details on PGS-COM can be found in Refs. [1,2]).

This approach allows to accurately estimate the annual profit of the designed plant as it takes into account of its part-load efficiency and expected heat demand profile. Moreover, it is worth noting that, since the part-load operation is optimized for each design solution and the two optimization levels (i.e., design optimization performed by PGS-COM and operation optimization performed by SQP) consider equivalent objective functions, the proposed twolevel approach is equivalent to the simultaneous optimization of design and operation variables (a proof can be found in Ref. [33]). Indeed, at the lower-level (optimization of part-load operation) in

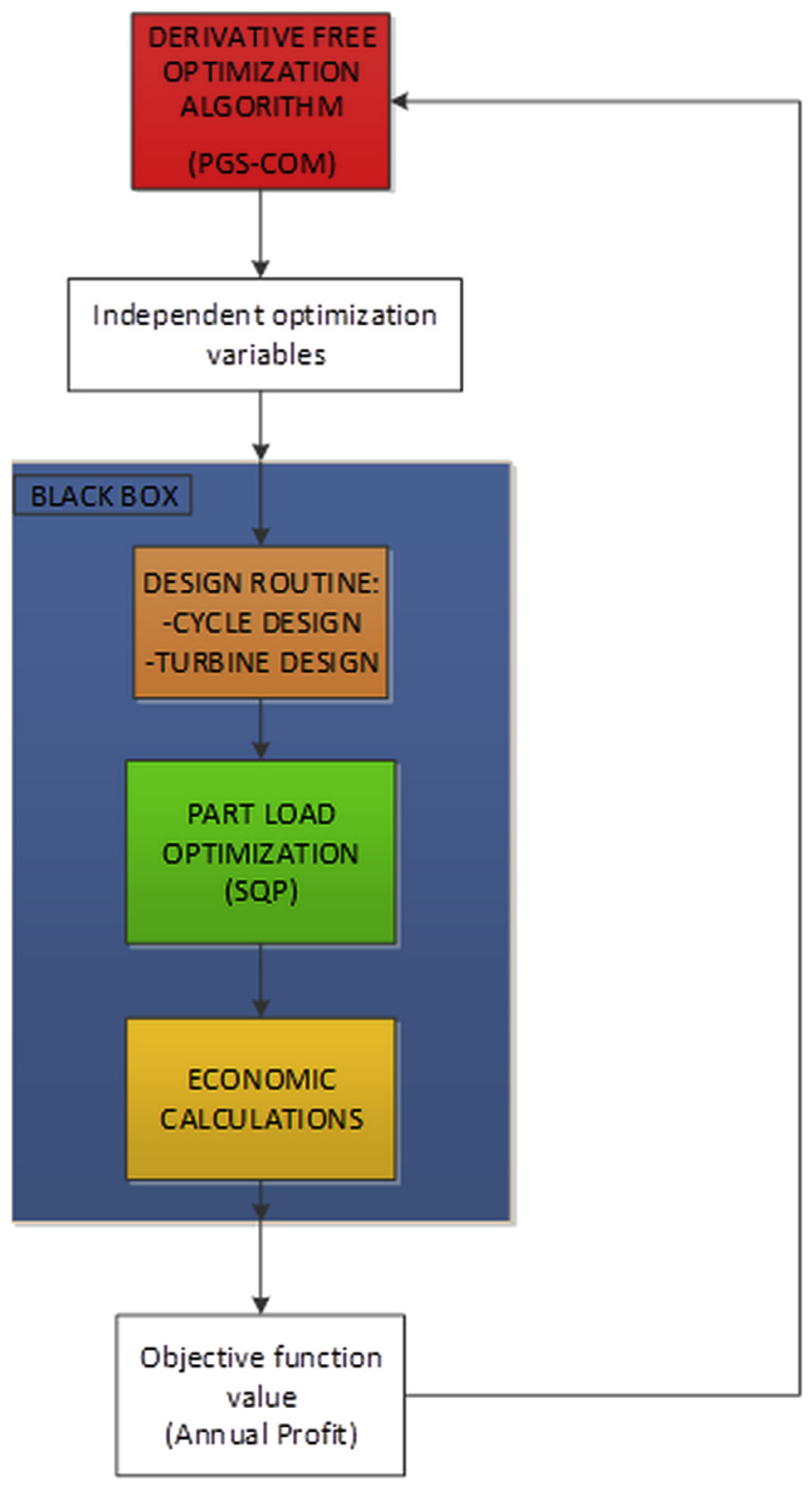

Fig. 11. Block-flow scheme of the proposed optimization methodology. which design variables and then investment costs are fixed, maximizing the gross margin $G M_{\mathrm{t}}$ for each time period $t$ is equivalent to maximize the annual profit of the plant.

The advantages of the two-level approach compared to a simultaneous one are (i) the minor risk of finding local optima due to the lower number of optimization variables of the two levels, (ii) the possibility of using ad hoc optimization algorithms for each problem (tackling the small-scale discontinuous design problem with a robust derivative-free method, and the larger-scale partload operation problem with a more efficient gradient-based algorithm).

The independent design variables optimized at the upper-level by PGS-COM are the size of the plant (nominal thermal power of the condenser), the evaporation and condensation pressures, the pinch point temperature differences in the main heat exchanger and regenerator, the turbine rotational speed and the expansion ratio of each stage the number of turbine stages is indirectly optimized, as explained in Part A of this work [1]. It is important to note that the size of the plant can be optimized because, thanks to the use of the turbine by-pass stream represented in Fig. 1, it is possible to undersize the plant (e.g., design the plant for a nominal condenser thermal power lower than the peak power required by the heat user) and open the by-pass to satisfy the peak heat demand.

\section{Test cases}

The two-level algorithm has been tested on the same test case considered in Part A [1] which represents a real-world application: optimize the design of a biomass-fired combined heat and power ORC for a district heating network of a residential area. The comparison with the results of Part A [1] allows also to evaluate the gain of annual profit which can be achieved by taking into account of the heat demand duration curve and of the optimal part-load operation of the ORC early at the design stage, and by optimizing the design for the optimal part-load operation. Input data and assumptions for the test case are reported in Tables $1,2,3$, and 4 of Part A [1] while the expected heat load duration curve of the district heating network is published in Ref. [34] and reported in Fig. 12. Like in Part A, toluene and MDM are considered as candidate working fluids, and for each fluid, the ORC plant is optimized for three electricity selling prices, $80 € / \mathrm{MWh}, 110 € /$ MWh, and $140 € / \mathrm{MWh}$ because the electricity price has a great effect on the optimal design. Upper and lower bounds of the independent design variables are reported in Table 2.

The lower bound of the condenser thermal power (plant size) has been set on the basis of preliminary computational tests. It is the minimum size of the plant required to generate the peak value of heat demand (i.e., $5300 \mathrm{~kW}$ ) by using the turbine by-pass stream. The selection criteria of the other bounds are discussed in Part A [1].

Before applying the two-level algorithm, it is necessary to discretize the heat-demand duration curve converting the continuous curve into a piece-wise constant curve so as to identify a finite set of part-load operating conditions. Indeed, in order to evaluate the annual operation of the plant, the NLP optimization problem associated to part-load operation must be solved for each heat demand level of the heat user. Six operative periods have been identified and their durations and heat demand values have been determined so as to approximate the original continuous curve, as shown in Fig. 12. A higher number of operating periods would provide a more accurate approximation of the heat-demand duration curve, however it would increase the computational time required to evaluate the black-box of Fig. 11. It is worth noting that with six operative periods, the evaluation of the black-box 


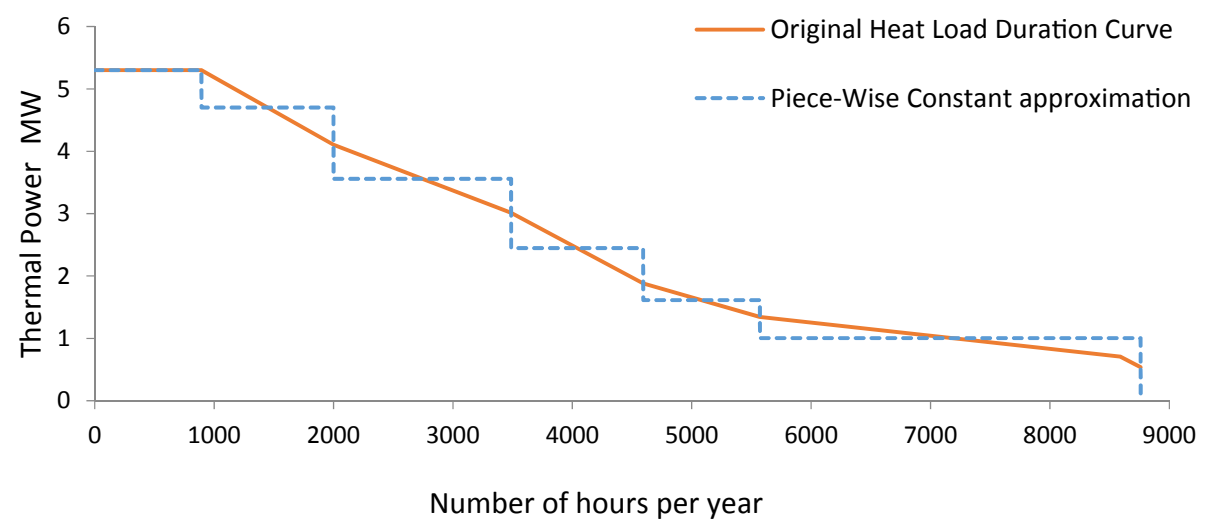

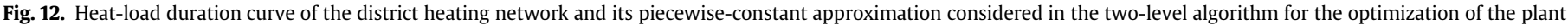
operation over the year.

Table 2

Upper and lower bounds of the independent design variables.

\begin{tabular}{lcc}
\hline & Lower bound & Upper bound \\
\hline Plant size (condenser nominal thermal power), kW & 4700 & 5300 \\
Evaporation Pressure, $\mathrm{kPa}$ & 300 & Critical pressure \\
Superheating degree, $\mathrm{K}$ & 1 & 75 \\
Pinch point temperature diff. of the MHE, K & 1 & 70 \\
Pinch point temperature diff. of the regenerator, K & 10 & 70 \\
Condenser pressure, $\mathrm{kPa}$ & 1000 & 200 \\
Turbine rotational speed, rpm & 1 & 20,000 \\
Stage pressure ratio $(-)$ & & 20 \\
\hline Constraint on the condenser pinch point temperature difference, $\geq 1{ }^{\circ} \mathrm{C}$ & \\
\hline
\end{tabular}

function (in which the NLP problem related to the optimal operation problem is solved five times) takes on average $2.6 \mathrm{~s}$.

With the aim of reducing the computational time and the risk of finding a local optimum, the optimal design solutions found in Part [A] (considering the number of full-load equivalent hours) have been used as starting points of the two-stage algorithm. Each optimization has been repeated 5 times, each one with 10,000 function evaluations (corresponding to $14 \mathrm{~h}$ on an Intel Xeon 2.8 $\mathrm{GHz}$ 12-core computer). The convergence curve (plot of the objective function value of the best current solution as a function of the number of function evaluations) for test PL-140 reported in Fig. 13 shows that the number of function evaluations is sufficient to achieve convergence of the PGS-COM algorithm.

Results are reported in Table 3 for cycles using toluene and Table 4 for cycles using MDM. PR-140, PR-110 and PR-80 label the designs optimized with the design algorithm presented in Part $\mathrm{A}$ [1] for the three electricity prices $(140,110$ and $80 € / \mathrm{MWh})$, while PL-140, PL-110 and PL-80 label the designs optimized with the two-stage algorithm proposed in this part. In order to make a fair comparison between cases PR and PL, the actual annual profit of all solutions is determined by simulating the optimal operation of the cycles over the whole year with the discretization of the heatdemand duration curve. Note that such a value is lower than that estimated in Part A [1] on the basis of the full-load equivalent hours since it takes into account the part-load efficiency of the cycle (which is lower than that at full-load).

Results in Tables 3 and 4 show that the simultaneous optimization of the design and part-load operation leads to an increase of the annual profit up to $22 \%$ (for case PR-80 with toluene), with an average value of $11 \%$ for designs with toluene, and $14 \%$ for those with MDM. This gain of profit is mainly due to the saving of capital cost. For instance, compared to designs PR, all designs PL are undersized and use the turbine by-pass stream to satisfy the peak demand of thermal power. Of course, the lower is the electricity price, the smaller is the optimal size of the plant (indicated by the condenser thermal power reported in Tables 3 and 4). Other important differences between designs PR and designs PL concern the evaporation and condensation pressures, superheating degrees, and pinch point temperature differences. It is worth noting that essentially all designs PL use higher condensation pressures, lower superheating degree, and larger pinch point temperature differences (specially for the condenser) compared to designs PR. This general trend is due to the fact that such design choices tend to decrease the capital cost of the cycle components without significantly penalizing the average efficiency of the cycle during the expected operation period. Indeed, at part-load, the condensation pressure naturally decreases, the superheating degree increases, and the pinch point temperature differences of the heat exchangers decreases, causing a rise of the cycle efficiency. Another important peculiarity is the fact that all designs PL have higher evaporation pressures than PR. This is due to two main reasons: (1) since during operation at part-loads (most of the hours) the evaporation pressure is decreased by the optimized control strategy, its value gets closer to the optimal efficiency value, (2) setting a higher design value of evaporation pressure reduces the risk of premature evaporation in the regenerator (which occurs at higher temperature), and then it allows to adopt the sliding-pressure mode (the most efficient one) for lower loads with a benefit on the part-load efficiency.

As far as the comparison between the two working fluids is concerned, it is worth noting that for the highest electricity price scenario (cases PL-140) there is only a negligible difference between the design-load net electric efficiency and the capital costs of the two cycles. However the cycle using toluene has a larger optimal size and this is advantageous for the plant revenues (larger electric power output). As a result, plant PL-140 with toluene 


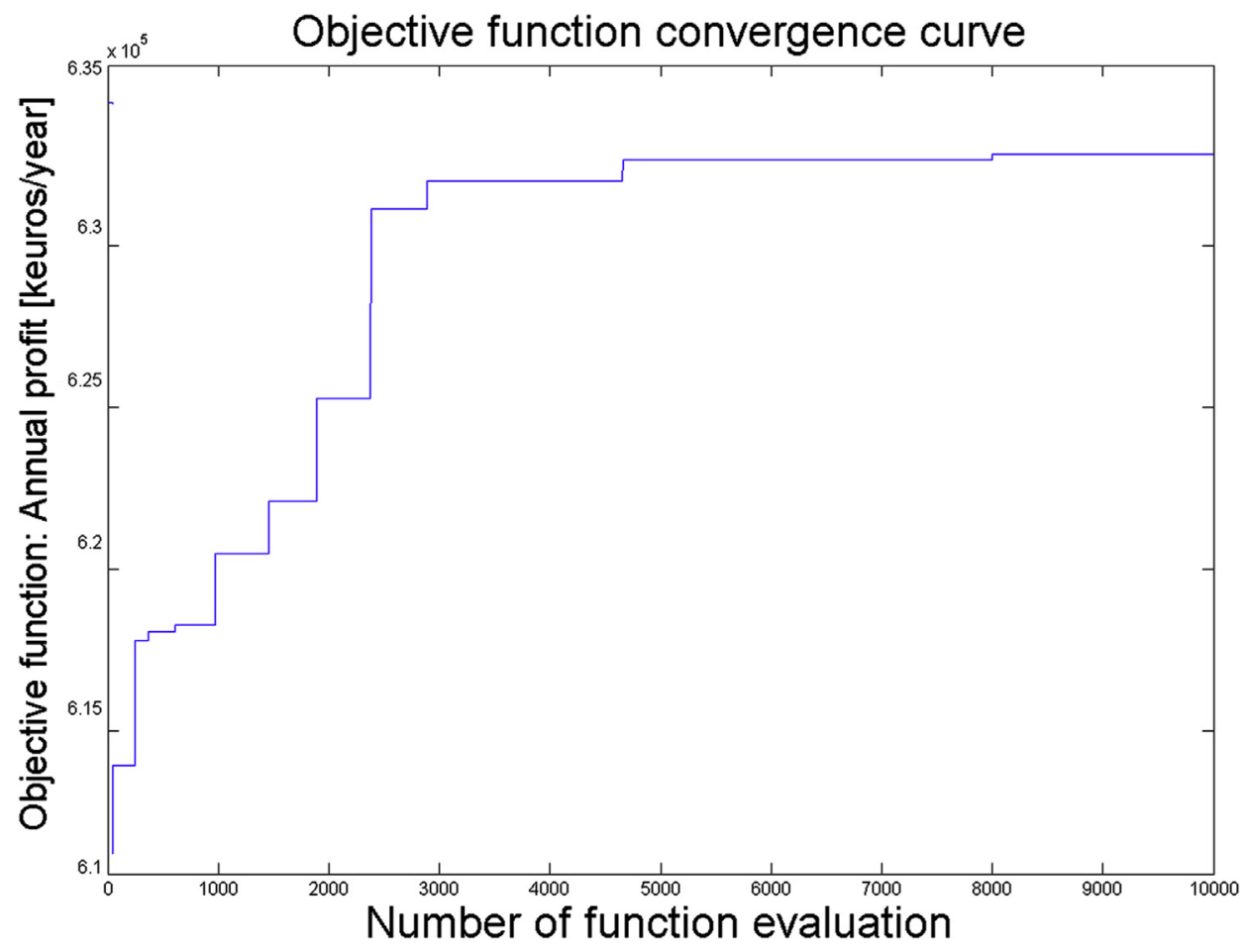

Fig. 13. Convergence curve of PGS-COM for test case PL-140 (relative to the best run).

achieves an $8 \%$ higher annual profit. For lower electricity prices the difference of annual profit between the toluene and MDM designs tends to increase: $10.7 \%$ for the electricity price of $110 € / \mathrm{MWh}$, and $14.4 \%$ for the electricity price of $80 € / \mathrm{MWh}$. Thus, also when considering part-load operation, toluene turns out to be better than MDM in terms of cycle efficiency and economic profit.

The part-load operation strategies of designs PL-140 and PL-110 with toluene and MDM are similar to those of designs PR-140 and PR-110 described in Section 2, with the difference that at the peak load condition the turbine by-pass is partially opened. Instead, the part-load operation strategy of designs PL-80 are worth analyzing since they are significantly undersized, and their cycle is quite different from that with maximum efficiency. The plot in Fig. 14 reports the net electric efficiency and the thermal efficiency of design PL-80 with toluene as a function of the condenser load. Fig. 15 shows the plot of evaporation pressure and the turbine admission pressure as a function of the condenser load. At $100 \%$ load (peak demand of heat), the evaporation pressure is lower than the design value since part of the vapor flow rate by-passes the turbine. Then, as the heat demand decreases, the bypass is

Table 3

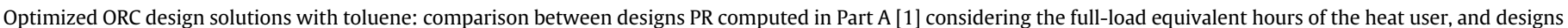

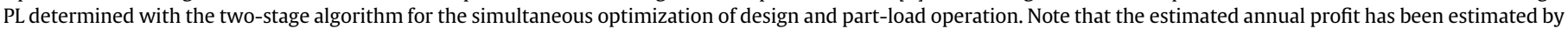

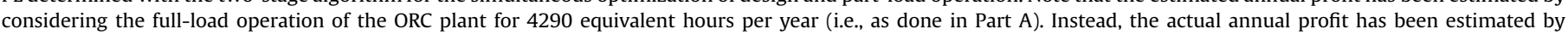
simulating the annual part-load operation of the ORC plant indicated by the heat-demand duration curve.

\begin{tabular}{|c|c|c|c|c|c|c|}
\hline Designs with toluene & PL-140 & PR-140 & PL-110 & PR-110 & PL-80 & PR-80 \\
\hline Evaporation pressure, $\mathrm{kPa}$ & 2578.91 & 2190.1 & 2757.14 & 2136 & 1706.96 & 998.7 \\
\hline Evaporation temperature (dependent variable), $\mathrm{K}$ & 551.38 & 535.4 & 559.61 & 540.52 & 496.98 & 489.9 \\
\hline Condenser Thermal Power (cycle size), kW & 5144.74 & 5300 & 4709.4 & 5300 & 4702.74 & 5300 \\
\hline Superheating degree, $\mathrm{K}$ & 11.85 & 29.8 & 7.82 & 31.63 & 38.58 & 75.0 \\
\hline Pinch point temp. diff. MHE, K & 2.72 & 1.0 & 2.52 & 1 & 5.01 & 8.3 \\
\hline Pinch point temp. diff. regenerator, $\mathrm{K}$ & 4.8 & 4.67 & 7.84 & 7.34 & 21.47 & 20.1 \\
\hline Condenser pressure, $\mathrm{kPa}$ & 59.51 & 41.05 & 55.29 & 44.93 & 137.67 & 66.79 \\
\hline Pinch point temp. diff. of condenser (dependent variable), K & 13.43 & 2.09 & 11.41 & 5 & 44.02 & 18.43 \\
\hline Turbine rotational speed, rpm & 20,000 & 20,000 & 20,000 & 20,000 & 19,862 & 20,000 \\
\hline Number of turbine stages (dependent variable) & 2 & 2 & 2 & 2 & 1 & 1 \\
\hline Pressure ratio of 1 st stage & 4.76 & 5.139 & 5.77 & 4.86 & 12.40 & 18.081 \\
\hline Pressure ratio of 2nd stage & 9.1 & 10.381 & 8.64 & 9.77 & - & - \\
\hline Nominal electric efficiency (design-load), \% & 18.07 & 21.01 & 19.38 & 20.60 & 13.06 & 15.04 \\
\hline Nominal power output (design-load), kW & 1394.7 & 1706.5 & 1358.8 & 1661.4 & 830.13 & 1110.90 \\
\hline Fuel thermal input LHV basis (design-load), kW & 7720.4 & 8122.1 & 7012.2 & 8065.4 & 6358.64 & 7384.51 \\
\hline ORC mass flow rate (design-load), $\mathrm{kg} / \mathrm{s}$ & 13.52 & 13.69 & 11.65 & 13.62 & 12.10 & 13.25 \\
\hline Oil mass flow rate (design-load), $\mathrm{kg} / \mathrm{s}$ & 60.25 & 48.87 & 78.43 & 46.91 & 22.46 & 29.05 \\
\hline Investment cost, $\mathrm{k} €$ & 5071.2 & 5346.0 & 4807.0 & 5261.4 & 4159.4 & 4593.4 \\
\hline Estimated Annual profit (full-load eq. hours), k€/year & n.a. & 691.59 & n.a. & 472.19 & n.a. & 255.86 \\
\hline Actual Annual profit (part-load operation), k€/year & 632.63 & 611.16 & 453.37 & 414.22 & 284.76 & 233.53 \\
\hline Actual Pay back time, years & 9 & 9 & 12 & 13 & 15 & 18 \\
\hline
\end{tabular}


Table 4

Optimized ORC design solutions with MDM: comparison between designs PR computed in Part A [1] considering the full-load equivalent hours of the heat user, and designs

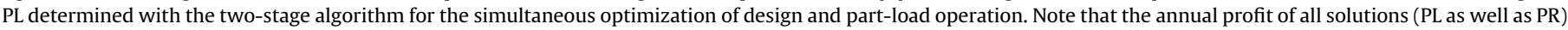
is estimated by simulating the annual operation of the cycles.

\begin{tabular}{|c|c|c|c|c|c|c|}
\hline Designs with MDM & PL-140 & PR-140 & PL-110 & PR-110 & PL-80 & PR-80 \\
\hline Evaporation pressure, $\mathrm{kPa}$ & 1358.56 & 985.56 & 1372.85 & 865.04 & 557.24 & 399.00 \\
\hline Evaporation temperature (dependent variable), K & 544.88 & 525.4 & 547.68 & 501.2 & 451.74 & 487.3 \\
\hline Condenser Thermal Power (cycle size), kW & 4733.44 & 5300.00 & 4758.55 & 4793.16 & 4702.74 & 5300.00 \\
\hline Superheating degree, $\mathrm{K}$ & 10.58 & 31.92 & 1.00 & 40.20 & 57.81 & 1.00 \\
\hline Pinch point temp. diff. MHE, K & 1.02 & 1.00 & 1.00 & 1.00 & 5.54 & 70.0 \\
\hline Pinch point temp. diff. regenerator, $\mathrm{K}$ & 8.76 & 6.63 & 11.93 & 11.99 & 60.86 & 39.4 \\
\hline Condenser pressure, $\mathrm{kPa}$ & 19.31 & 10.00 & 21.92 & 10.13 & 52.42 & 31.24 \\
\hline Pinch point temp. diff. of condenser (dependent variable), $\mathrm{K}$ & 21.10 & 3.7 & 25.24 & 42.65 & 59.05 & 39.87 \\
\hline Turbine rotational speed, rpm & $15,212.11$ & $10,950.08$ & $20,000.00$ & $11,266.02$ & $19,318.17$ & 17,845 \\
\hline Number of turbine stages (dependent variable) & 2 & 2 & 2 & 2 & 1 & 1 \\
\hline Pressure ratio of 1 st stage & 5.17 & 6.57 & 5.51 & 5.69 & 10.63 & 15.24 \\
\hline Pressure ratio of 2 nd stage & 13.61 & 15.01 & 11.36 & 15.01 & - & - \\
\hline Nominal electric efficiency (design-load), \% & 18.09 & 19.953 & 16.91 & 12.666 & 8.33 & 9.352 \\
\hline Nominal power output (design-load), kW & 1268.01 & 1626.98 & 1161.54 & 916.53 & 494.69 & 633.24 \\
\hline Fuel thermal input LHV basis (design-load), kW & 7010.37 & 8153.73 & 6868.06 & 7235.92 & 5935.40 & 6771.16 \\
\hline ORC mass flow rate (design-load), $\mathrm{kg} / \mathrm{s}$ & 21.41 & 27.44 & 23.26 & 26.62 & 17.32 & 22.36 \\
\hline Oil mass flow rate (design-load), kg/s & 44.31 & 49.25 & 26.90 & 39.22 & 14.25 & 65.20 \\
\hline Investment cost, k€ & 4948.55 & 5536.01 & 4839.48 & 5385.62 & 3898.49 & 9.352 \\
\hline Estimated Annual profit (full-load eq. hours), k€/year & n.a. & 603.47 & n.a. & 395.41 & n.a. & 211.21 \\
\hline Actual Annual profit (part-load operation), k€/year & 581.79 & 511.64 & 404.66 & 343.77 & 243.64 & 219.48 \\
\hline Actual Pay back time, years & 9 & 11 & 12 & 16 & 17 & 21 \\
\hline
\end{tabular}

progressively closed the evaporation rises up to the maximum value (for $90 \%$ of the condenser load). At lower loads, the slidingpressure control mode is adopted and the evaporation pressure decreases so as to decrease the vapor flow rate. However, at about $35 \%$ of the load, the evaporation pressure changes trend (below 35\% of the load, pressure is increased at lower loads) so to avoid the premature evaporation of liquid in the regenerator.

\section{Conclusions}

The main objective of this two-part publication is to describe and show the effectiveness of a novel design optimization approach for Combined Heat and Power Organic Rankine Cycles capable of simultaneously optimizing the plant design and part-load operation. With a two-level strategy, at the upper level the direct-search derivative-free algorithm (PGS-COM) optimizes the independent

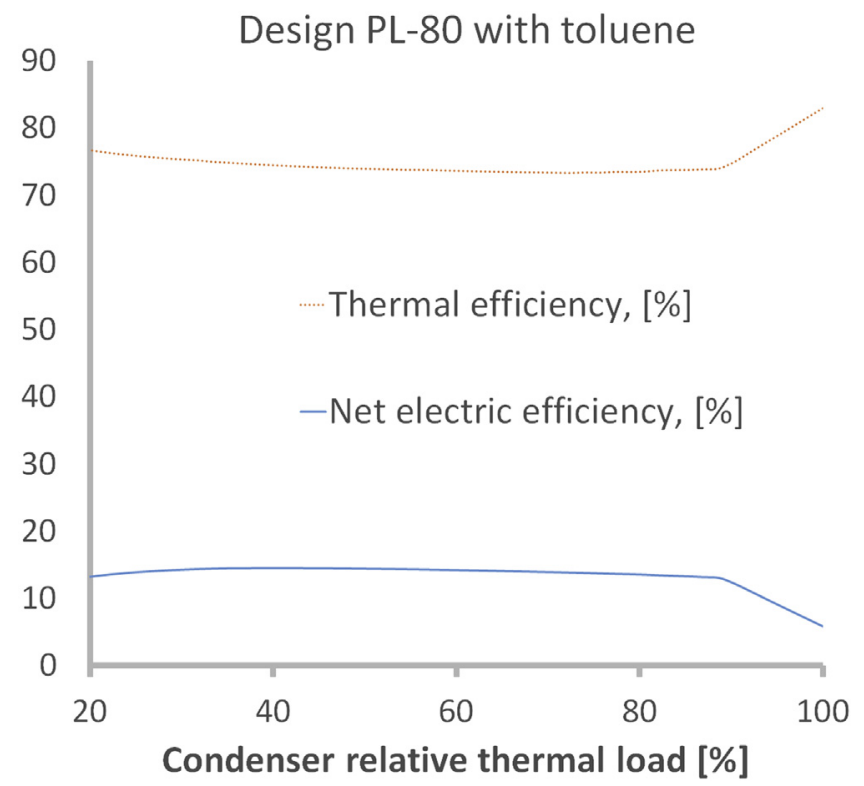

Fig. 14. Net electric efficiency and the thermal efficiency of design PL-80 with toluene as a function of the condenser load. design variables, and at the lower level the cycle is designed with the algorithm proposed in Part A [1] and its part-load operation is numerically optimized with the algorithm proposed in this paper. The objective function can be any thermodynamic or economic performance index.

The computational results obtained for a medium size biomassfired Combined Heat and Power Organic Rankine Cycle show that, (1) formulating the part-load optimization problem as a nonlinear optimization problem and tackling it with the Sequential Quadratic Programming algorithm appear to be particularly efficient in terms of computational time, (2) in spite of the part-load problem nonconvexity, a thorough analysis of the optimized solutions indicates that the Sequential Quadratic Programming algorithm likely converges to globally optimal solutions, (3) thanks to the parallelcomputing capability of PGS-COM and the use of a multiple-core computer, the computational time required by the two-stage algorithm is not prohibitive, about $14 \mathrm{~h}$. This feature makes the approach an effective design tool not only for research but also for the industrial sector.

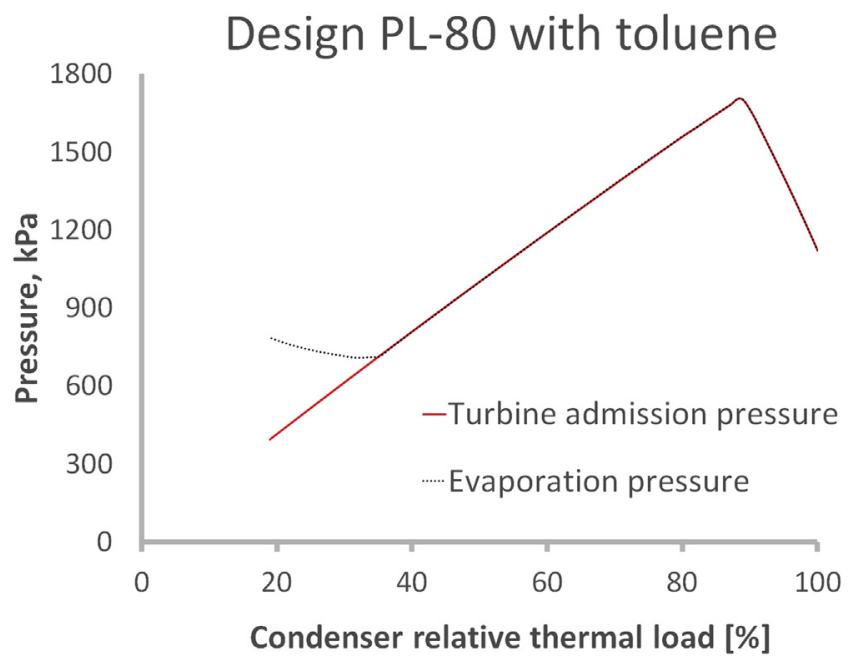

Fig. 15. Plot of the evaporation and turbine admission pressures of design PL-80 using toluene with respect to the condenser relative thermal load (thermal power/design thermal power of the condenser). 
Results indicate that there is a substantial advantage in considering part-load operation early at the design stage of the plant. Indeed, the ORC plant designs optimized considering also part-load operation (designs "PL" described in Section 4 of this paper) lead to a considerably higher annual profit (up to $22 \%$ higher) compared to designs optimized in Part A [1] considering only full-load operation for the given number of equivalent hours (designs "PR", as described in Part A). In particular, with respect to designs "PR", essentially all designs "PL" are slightly undersized and use the turbine bypass to satisfy the peak load, and have higher evaporation and condensation pressures, lower superheating degrees, and larger pinch point temperature differences. Such design choices allow to save capital cost without significantly penalizing the part-load efficiency of the plant.

As far as the optimal part-load operation strategy is concerned, all designs are controlled following the sliding-pressure mode at high loads, and with a combination of sliding-pressure and throttling at low loads where the sliding-pressure mode cannot be applied because premature evaporation occurs in the regenerator. Advantageous expedients used by the optimizer to limit this issue are: (1) use the turbine admission valve to increase the evaporator pressure while decreasing the turbine admission pressure, (2) adopt high design values of the evaporation pressure so as to extend the load range in which the sliding-pressure mode (the most efficient one) can be adopted.

\section{Acknowledgments}

The authors acknowledge Tobias Erhart, Researcher at the University of Applied Sciences Stuttgart, for the useful information required to reproduce the part-load control strategy of the "Scharnhauser Park" ORC plant. The authors acknowledge also LEAP (Laboratorio Energia Ambiente Piacenza) and the Italian Ministry of the Environment and Protection of Land and Sea ("Ministero dell'Ambiente e della Tutela del Territorio e del Mare") for partially funding the research activity of Federico Capra. Indeed, this study was economically supported by the Italian Ministry of the Environment and Protection of Land and Sea within the framework of the research project "CUBIS - Cogenerazione Urbana da Biomasse e Solare" (CUP F81C07000120003) granted to LEAP.

\section{Nomenclature}

BFGS Broyden, Fletcher, Goldfarb, Shanno hessian approximation

CHP combined heat and Power

LCCR levelized capital charge rate

LHV lower heating value

MDM otcamethyltrisiloxane working fluid

MHE main (Thermal oil-working fluid) heat exchanger

NLP nonlinear program

ORC Organic Rankine cycle

PGS-COM pattern generating set complex optimization algorithm

PR plant designs optimized for maximum annual profit without considering part-load operation

PL plant designs optimized for maximum annual profit with simultaneous optimization of part-load operation

SQP sequential quadratic programming

\section{Symbols}

$\boldsymbol{x} \quad$ vector of optimization variables

lb lower bounds of the optimization variables

$\boldsymbol{u b}$ upper bounds of the optimization variables

g vector of inequality constraints of the optimization problem

\section{References}

[1] Martelli E, Capra F, Consonni S. Numerical optimization of CHP Organic Rankine Cycles - part A: design optimization [Submitted for publication] Energy 2015.

[2] Martelli E, Amaldi E. PGS-COM: a hybrid method for constrained non-smooth black-box optimization problems brief review, novel algorithm and comparative evaluation. Comput Chem Eng 2014;63(17):108-39.

[3] Biegler LT, Grossmann IE, Westerberg AW. Systematic methods of chemical process design. Upper Saddle River, New Jersey 07458: Prentice Hall PTR; 1997.

[4] Invernizzi CM. Closed power cycles - thermodynamic fundamentals and applications. London: Springer-Verlag; 2013.

[5] Sun J, Li W. Operation optimization of an organic rankine cycle (ORC) heat recovery power plant. Appl Therm Eng Aug. 2011;31(11-12):2032-41.

[6] Rosenbrock HH. An automatic method for finding the greatest or least value of a function. Comput J 1960;3:175-84.

[7] Muñoz de Escalona JM, Sánchez D, Chacartegui R, Sánchez T. Part-load analysis of gas turbine \& ORC combined cycles. Appl Therm Eng Apr. 2012;36: 63-72.

[8] Ghasemi H, Paci M, Tizzanini A, Mitsos A. Modeling and optimization of a binary geothermal power plant. Energy 2013;50:412-28.

[9] Calise F, Capuozzo C, Carotenuto A, Vanoli L. Thermoeconomic analysis and off-design performance of an organic Rankine cycle powered by mediumtemperature heat sources. Sol Energy May 2014;103:595-609.

[10] Klein SA. "Engineering Equation Solver (EES), http://www.fchart.com/ ees/." [accessed 31.05.15].

[11] Manente G, Toffolo A, Lazzaretto A, Paci M. An Organic Rankine Cycle offdesign model for the search of the optimal control strategy. Energy 2013;58:97-106

[12] MathWorks. "Simlulink, http://www.mathworks.com/products/simulink/ index.html?s_tid=gn_loc_drop." [accessed 31.05.15].

[13] MathWorks. "Optimization Toolbox, http://it.mathworks.com/products/ optimization/." [accessed 31.05.15].

[14] Wang J, Yan Z, Zhao P, Dai Y. Off-design performance analysis of a solarpowered organic Rankine cycle. Energy Convers Manag 2014;80:150-7. Hu

[15] D, Li S, Zheng Y, Wang J, Dai Y. Preliminary design and off-design performance analysis of an Organic Rankine Cycle for geothermal sources. Energy Convers Manag 2015;96:175-87.

[16] Ibarra M, Rovira A, Alarcón-Padilla DC, Blanco J. Performance of a $5 \mathrm{kWe}$ Organic Rankine Cycle at part-load operation. Appl Energy 2014;120:147-58.

[17] Lecompte S, Huisseune H, van den Broek M, De Schampheleire S, De Paepe M. Part load based thermo-economic optimization of the Organic Rankine Cycle 
(ORC) applied to a combined heat and power (CHP) system. Appl Energy Nov. 2013;111:871-81.

[18] Toffolo A, Lazzaretto A, Manente G, Paci M. A multi-criteria approach for the optimal selection of working fluid and design parameters in Organic Rankine Cycle systems. Appl Energy 2014;121:219-32.

[19] Song J, Li Y, Gu C, Zhang L. Thermodynamic analysis and performance optimization of an ORC (Organic Rankine Cycle) system for multi-strand waste heat sources in petroleum refining industry. Energy Jul. 2014;71:673-80.

[20] Song J, Song Y, Gu C. Thermodynamic analysis and performance optimization of an Organic Rankine Cycle (ORC) waste heat recovery system for marine diesel engines. Energy 2015;82:976-85.

[21] Lagarias JC, Reeds J a, Wright MH, Wright PE. Convergence properties of the Nelder-Mead simplex method in low dimensions. SIAM J Optim Jan. 1998;9(1):112-47.

[22] Forsythe G, Malcolm M, Moler C. Computer methods for mathematical computation. 1st ed. Prentice Hall PTR; 1976.

[23] Toffolo A, Lazzaretto A, Morandin M. The HEATSEP method for the synthesis of thermal systems: an application to the S-Graz cycle. Energy 2010;35(2): 976-81.

[24] Thermoflow. "Thermoflex v. 24 combinedcycle_TFX.html." [accessed 31.05.15].

[25] Lemmon EW, Huber ML, and Mclinden MO. "NIST reference fluid thermodynamic and transport properties - REFPROP," NIST Standard Reference Database 23, http://www.nist.gov/srd/nist23.cfm [accessed 31.05.15].
[26] Colonna P, Nannan NR, Guardone A. Multiparameter equations of state for siloxanes. Fluid Phase Equilib 2008;263:115-30.

[27] Lemmon EW, Span R. Short fundamental equations of state for 20 industrial fluids. J Chem Eng Data 2006;51:785-850.

[28] MathWorks. "Matlab, www.mathworks.it/products/matlab." [accessed 31.05.15].

[29] Nocedal J, Wright SJ. Numerical optimization. 2nd ed. New York: Springer; 2006. ISBN: 0-387-30303-0.

[30] Erhart T, Strzalka R, Eicker U, Infield D. Performance analysis of a biomass ORC poly-generation system. In: 2nd European Conference on Polygeneration, Terragona, Spain; 2011. p. 1-11.

[31] Erhart TG, Eicker U, Infield D. Influence of condenser conditions on organic rankine cycle load characteristics. J Eng Gas Turbines Power Mar. 2013;135(4):042301.

[32] EPRI (Electric Power Research Institute). EPRI Report TR-102275. TAG technical assessment guide (electric supply), vol. 1; 1993. Rev. 7.

[33] Martelli E. Numerical optimization of heat recovery steam cycles for highly integrated energy systems [PhD thesis]. Politecnico di Milano, Depertment of Energy; 2010.

[34] Tańczuk M, Ulbrich R. Implementation of a biomass-fired co-generation plant supplied with an ORC (Organic Rankine Cycle) as a heat source for small scale heat distribution system - a comparative analysis under polish and German conditions. Energy Dec. 2013;62:132-41. 